UNIVERSIDADE DE BRASÍLIA - UnB

FACULDADE DE ECONOMIA, ADMINISTRAÇÃO, CONTABILIDADE E CIÊNCIA DA INFORMAÇÃO E DOCUMENTAÇÃO - FACE

PROGRAMA DE PÓS-GRADUAÇÃO EM ADMINISTRAÇÃO - PPGA

MARIA LUIZA FERNANDES ARAÚJO

VALOR INSTRUMENTAL, SUPORTE À TRANSFERÊNCIA E IMPACTO DO TREINAMENTO NO TRABALHO EM CURSOS DE ESPECIALIZAÇÃO LATO SENSU

BRASÍLIA

SETEMBRO, 2009 
MARIA LUIZA FERNANDES ARAÚJO

\section{VALOR INSTRUMENTAL, SUPORTE À TRANSFERÊNCIA E IMPACTO DO TREINAMENTO NO TRABALHO EM CURSOS DE ESPECIALIZAÇÃO LATO SENSU}

Monografia apresentada no Curso de Especialização em Gestão de Pessoas do Programa de Pós-Graduação em Administração da Faculdade de Economia, Administração, Contabilidade e Ciência da Informação e Documentação - FACE, da Universidade de Brasília, como requisito final para obtenção do grau de especialista em Gestão de Pessoas.

Orientadora: Prof. Dra. Gardênia da Silva Abbad

BRASÍLIA

SETEMBRO, 2009 
MARIA LUIZA FERNANDES ARAÚJO

\section{VALOR INSTRUMENTAL, SUPORTE À TRANSFERÊNCIA E IMPACTO DO TREINAMENTO NO TRABALHO EM CURSOS DE ESPECIALIZAÇÃO LATO SENSU}

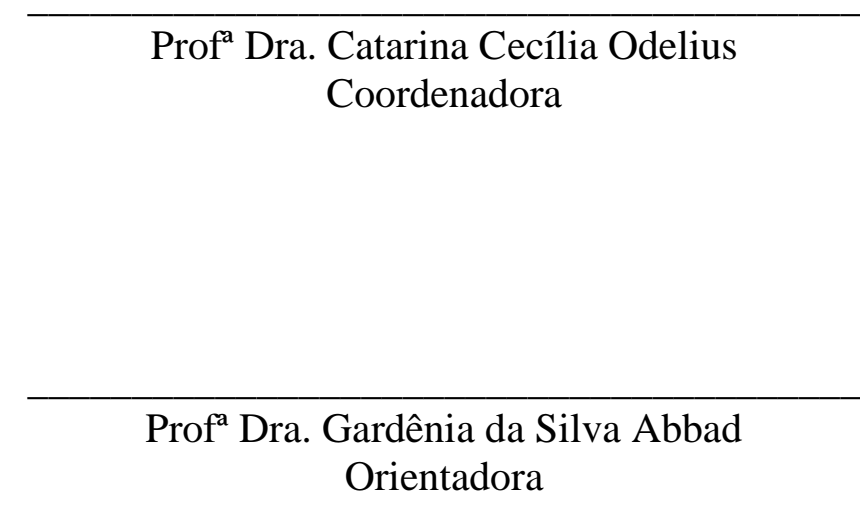

BRASÍLIA

SETEMBRO, 2009 


\section{AGRADECIMENTOS}

À minha orientadora, Gardênia Abbad, pela dedicação nos encontros do Grupo Impacto em que pude vivenciar a transferência do conhecimento. Espero mostrar com este trabalho o impacto desse aprendizado.

À minha co-orientadora, Daniela Borges, pelos momentos dedicados ao meu auxílio e acompanhamento. Aos nossos encontros e desencontros!

Aos colegas dos cursos de especialização que participaram dessa pesquisa.

Aos meus pais pelo amor, apoio e dedicação de sempre. Essa conquista também é de vocês!

À minha irmã, companheira de vida.

Ao meu namorado pelo carinho e companheirismo.

Ao meu amigo Carlos Eduardo, pelo carinho, disposição e auxílio com seus conhecimentos em tecnologia da informação.

Aos meus amigos queridos pelo apoio e momentos de descontração.

Aos colegas da V Turma do Curso de Especialização em Gestão de Pessoas da UnB, grandes pessoas, que agora também vivenciam essa vitória.

À vida! 


\section{RESUMO}

O presente estudo teve por objetivo principal investigar as percepções de impacto do treinamento no trabalho, suporte à transferência e valor instrumental de egressos em cursos de especialização lato sensu e analisar as possíveis relações existentes entre estes. O impacto do treinamento traduz os efeitos produzidos pelo evento instrucional nos níveis de desempenho, mas sabe-se que para que isso ocorra é necessário um conjunto de condições de apoio para que se consiga transferir o aprendizado para trabalho e também que o evento instrucional tenha um valor para o indivíduo, que esteja relacionado com resultados desejados, para que este se sinta motivado a aplicar o aprendizado. A pesquisa de caráter descritivo e prático utilizou-se de um instrumento de avaliação de impacto e de suporte à transferência e um instrumento de valor instrumental. A amostra da pesquisa foi de 39 egressos do Curso de Especialização em Gestão de Pessoas e do Curso de Gestão Organizacional. As análises descritivas demonstraram que os funcionários percebem a influência do curso em desempenhos genéricos; algumas vezes percebem ações organizacionais de suporte à transferência e; percebem o valor da especialização para alcance de objetivos pessoais e profissionais considerados importantes. As análises de correlação representaram que o impacto se correlaciona com instrumentalidade e com fatores situacionais de apoio. Outras correlações são entre fatores situacionais de apoio e conseqüências associadas ao uso das novas habilidades e valência e instrumentalidade. Os resultados confirmam os resultados de pesquisas anteriores que demonstram a relevância das condições contextuais do trabalho para garantir que os treinamentos proporcionados sejam efetivos e eficazes nas mudanças de desempenho. Além disso, verifica-se a importância de analisar os valores associados ao evento institucional para alcançar a efetividade do treinamento. Ao final do estudo, foram apresentadas suas limitações e recomendações acerca do tema.

Palavras-chave: Treinamento, Desenvolvimento e Educação, Impacto do Treinamento no Trabalho, Suporte à Transferência de Treinamento e Valor Instrumental do Treinamento. 


\section{SUMÁRIO}

Lista de Figuras .......................................................................... p. 08

Lista de Tabelas ................................................................................ p. p. 08

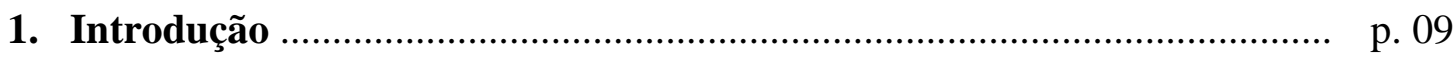

1.1. Pergunta de pesquisa ........................................................................ p. 11

1.2. Objetivos .................................................................................... p. 11

1.2.1. Objetivo Geral .................................................................. p. 11

1.2.2. Objetivos Específicos ........................................................... p. 11

1.3. Justificativa ............................................................................... p. p. 11

2. Referencial teórico …........................................................................... p. 13

2.1. Histórico da área de Gestão de Pessoas ................................................ p. 13

2.2. Sistema de TD\&E ........................................................................ p. 17

2.3. Avaliação de Treinamento .................................................................. p. 18

2.4. Avaliação de Impacto do Treinamento no Trabalho e seus preditores ... $\quad$ p. 23

2.5. Características motivacionais da clientela ........................................... p. 25

3. Método …........................................................................................... p. 29

3.1. Tipo de pesquisa .......................................................................... p. 29

3.2. Participantes da pesquisa ................................................................. p. 29

3.3. Instrumentos de coleta de dados ........................................................ p. 30

3.3.1. Questionário de Impacto do Curso no Trabalho .......................... p. p. 31

3.3.2. Questionário de Suporte à Transferência percebido pelos

Alunos ......................................................................................... p. 31

3.3.3. Questionário de Valor Instrumental do Curso ........................... p. 32

3.4. Procedimento de coleta e análise dos dados ........................................ p. 32

4. Resultados …............................................................................... p. 34

4.1. Resultados descritivos da variável Impacto em Amplitude .................. p. p. 34

4.2. Resultados descritivos da variável Suporte à Transferência ................... p. 35

4.3. Resultados descritivos da variável Valor Instrumental do Curso ........... p. 38

4.4. Análise da correlação entre as variáveis .............................................. p. 40

5. Discussão ….................................................................................... p. p. 41

6. Conclusões e Agenda de Pesquisa ……................................................. p. 45

6.1. Conclusões …............................................................................... p. 45 
6.2. Agenda de Pesquisa ...................................................................... p. 46

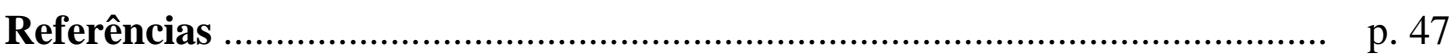

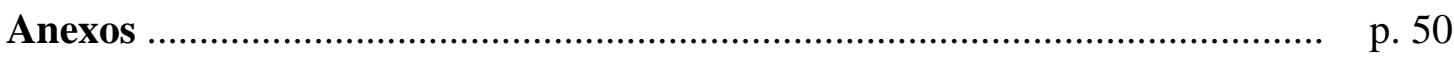

Anexo 1 - Questionário de Avaliação de Impacto do Curso ................................ p. 51

Anexo 2 - Questionário de Avaliação do Valor Instrumental do Curso .............. p. 54 


\section{LISTA DE FIGURAS}

Figura 1 - Modelo de Avaliação Integrado e Somativo - MAIS

p. 20

Figura 2 - Modelo de Avaliação do Impacto do Treinamento no Trabalho IMPACT

\section{LISTA DE TABELAS}

Tabela 1 - Resultados descritivos dos dados demográficos, funcionais e do curso

p. 30

Tabela 2. Informações gerais sobre os instrumentos utilizados na pesquisa

p. 31

Tabela 3 - Resultados descritivos do Impacto em Amplitude

p. 34

Tabela 4 - Resultados descritivos de Fatores Situacionais de Apoio

p. 35

Tabela 5 - Resultados descritivos de Suporte Material

p. 36

Tabela 6 - Resultados descritivos de Conseqüências Associadas ao Uso de Novas Habilidades

p. 37

Tabela 7 - Resultados descritivos da variável Valência

p. 38

Tabela 8 - Resultados descritivos da variável Instrumentalidade

p. 39

Tabela 9 - Correlação entre as variáveis

p. 40 


\section{INTRODUÇÃO}

As grandes transformações sociais, econômicas, tecnológicas e políticas que marcaram o século XX, trouxeram novos cenários para o mundo do trabalho. Para acompanhar e reagir à evolução do conhecimento científico e ao desenvolvimento tecnológico, as organizações começaram a ver a necessidade de investir em recursos e modelos de gestão que visassem o desenvolvimento de seus colaboradores com o objetivo de manter o nível de desempenho e produtividade e obter um diferencial que garanta sua presença no mercado.

As organizações perceberam que o seu sucesso estava cada vez mais determinado pelas habilidades, aptidões, talentos e experiências de seus funcionários e passaram a atribuir mais importância à gestão estratégica de recursos humanos, principalmente no que diz respeito ao desenvolvimento de competências profissionais.

Nesse cenário, surge, conforme Brandão e Guimarães (2001), uma tecnologia de gestão chamada de Gestão de Competências na qual sustenta que determinados atributos organizacionais são condicionantes do sucesso da empresa frente à concorrência. Esse processo de gestão trata-se de um processo contínuo que toma como referência a estratégia da empresa e direciona todas as suas ações de gestão de pessoas para captação e desenvolvimentos das competências necessárias para o atingimento dos seus objetivos.

Esses autores classificam competências como humanas, que estão relacionadas ao indivíduo ou à equipe de trabalho e as organizacionais, que referem-se às competências que dizem respeito à organização como um todo ou uma de suas unidades, ressaltando que o conjunto de competências profissionais, aliado a processos e outros recursos, é o que dá origem à competências organizacional.

Nesse sentido, sendo as competências organizacionais o resultado que gera vantagem e diferencial competitivo e as competências individuais ou profissionais, os conhecimentos, habilidades e atitudes necessárias para que o funcionário possa apresentar um desempenho adequado para o seu cargo, a Gestão de Competências tem a finalidade de identificar as competências organizacionais e alinhar com as competências individuais, revelando as competências ainda não desenvolvidas. Essas competências serão desenvolvidas, aprimoradas e disseminadas por meio de ações de aprendizagem formais, através de programas de Treinamento, Desenvolvimento e Educação (TD\&E), que é o foco desta pesquisa e ações nãoformais que estruturam-se por meio das relações sociais e culturais da organização.

O treinamento garante a aquisição sistemática de competências que resultam na melhoria do desempenho no trabalho. Apresenta quatro elementos principais, segundo 
Rosenberg (2001 apud VARGAS; ABBAD, 2006): intenção de melhorar um desempenho específico reflete a estratégia instrucional que melhor se adequa ao público-alvo, se preocupando com seu perfil, utiliza de meios pelos quais a instrução é dada, que podem incluir as diversas tecnologias, a combinação de diferentes abordagens, etc. e é passível e tem caráter de obrigatoriedade a avaliação, independente do nível que se deseja verificar.

O sistema de treinamento, segundo Borges-Andrade (2006b), possui os seguintes componentes: avaliação de necessidades, planejamento do treinamento e avaliação de treinamento. Esses componentes mantêm entre si um constante fluxo de informações e é a avaliação de treinamento que retroalimenta esse processo, aperfeiçoando o sistema.

A partir da descoberta dos valores estratégicos de uma ação de capacitação e dos esforços e investimentos despendidos nestas, há uma crescente demanda pela avaliação da efetividade desse processo, no qual uma das avaliações é a de impacto do treinamento. Essa tem o objetivo de avaliar se o indivíduo, após a aquisição de certos conhecimentos, habilidades e atitudes necessários para a sua função, apresenta melhorias significativas no seu desempenho.

Entretanto, a efetividade de um evento instrucional não depende apenas do evento em si, mas sim de fatores ligados às características do contexto de trabalho, tais como o suporte à transferência, e de fatores individuais, tais como variáveis demográficas, cognitivas, afetivas, motivacionais, dentre outras.

O suporte à transferência exprime a percepção do participante a respeito do nível de apoio que recebe da organização, representada por chefes, colegas e pares, para usar de modo eficaz, no trabalho, as novas habilidades adquiridas (ABBAD et al., 2006).

As características da clientela podem auxiliar na busca por altos níveis de transferência do aprendido, já que o estabelecimento de estratégias coerentes com o perfil traçado auxilia no sucesso do evento instrucional e assim corrobora para essa transferência. Dentre as variáveis de características da clientela, o estudo visa abordar o Valor Instrumental do Treinamento, que seria a percepção do indivíduo de que as novas habilidades adquiridas serão úteis para atingir recompensas em sua vida profissional e pessoal.

Dessa forma, neste estudo serão abordados os construtos de Impacto do Treinamento no Trabalho, Suporte à Transferência e Valor Instrumental do Treinamento.

\subsection{Pergunta de pesquisa}


A intenção deste estudo é pesquisar qual a correlação entre as percepções de impacto, suporte e valor instrumental de egressos em especialização lato sensu.

\subsection{Objetivos}

\subsubsection{Objetivo Geral}

O objetivo geral deste estudo é correlacionar percepção de impacto, suporte e valor instrumental de egressos em especialização lato sensu.

\subsubsection{Objetivos específicos}

- Analisar os conceitos de treinamento e avaliação de treinamento;

- Analisar os conceitos de impacto do treinamento e seus preditores;

- Analisar algumas características de clientela do treinamento;

- Identificar percepções acerca do valor instrumental do curso;

- Identificar percepções acerca do suporte à transferência do aprendizado;

- Identificar percepções acerca do impacto do curso no trabalho;

- Relacionar as variáveis Impacto do Treinamento no Trabalho, Suporte à Transferência e Valor Instrumental do Treinamento.

\subsection{Justificativa}

A partir das mudanças nas instituições advindas do progresso científico e tecnológico, novas habilidades estão sendo exigidas dos trabalhadores, o que torna os eventos educacionais em TD\&E essenciais no desenvolvimento dessas competências.

Essas ações, por sua vez, demandam altos investimentos das empresas, o que exige uma avaliação da eficácia dos efeitos desses programas no desempenho das pessoas.

Segundo Freitas; Borges-Andrade; Abbad; Pilati (2006), avaliar a contribuição de TD\&E para o desempenho dos indivíduos e da organização é uma ação estratégica para a área de gestão de pessoas, pois pode trazer como os processos da área podem favorecer o alcance dos resultados da organização. Assim possui dois propósitos fundamentais: o técnico que é o 
processo de retroalimentação do sistema de treinamento, ou seja, a melhoria contínua deste, e o político, que é o reconhecimento da área de TD\&E pela instituição.

Por estas razões, é essencial a produção de conhecimento na área de avaliação de treinamento, por mais que a produção científica tenha crescido bastante, há a necessidade de ampliação do foco do estudo, buscando a associação da eficácia dos treinamentos com variáveis situacionais e variáveis individuais.

Nesse sentido, mensurar o impacto do treinamento significa avaliar em que medida os esforços despendidos nestas ações efetivamente geraram os efeitos desejados. Mas sabe-se que para que um indivíduo transfira um conhecimento é necessário que esteja empenhado com as atividades do curso (motivação para aprender), motivado para aplicar o conhecimento aprendido (motivação para transferir) e acredite que o curso irá ajudar nas suas tarefas diárias (valor instrumental) (MENESES; ABBAD; ZERBINI; LACERDA, 2006).

Dessa forma, verificar a relação existente entre as variáveis Impacto do Treinamento no Trabalho, Suporte à Transferência e Valor Instrumental do Treinamento vai ao encontro das demandas organizacionais, pois procura a identificação de fatores individuais que interferem na transferência do aprendizado. 


\section{REFERENCIAL TEÓRICO}

A seguir será apresentada uma revisão da literatura acerca do histórico da área de gestão de pessoas, do sistema de TD\&E, da avaliação de treinamento e seus preditores, com o intuito de fundamentar a realização do presente trabalho.

\subsection{Histórico da área de Gestão de Pessoas}

Conforme França (2008) existem dois modelos básicos de gestão: o modelo diretivo e o modelo participativo. O modelo diretivo utiliza predominantemente a autoridade formal e a burocracia para obter obediência. Uma organização com esse modelo possui uma estrutura administrativa centralizada, são também chamadas de mecanicistas. Já no modelo participativo, predominam a liderança, a disciplina e a autonomia, na qual os colaboradores são responsáveis por seu próprio comportamento e desempenho. A partir da linha de pensamento dessa autora, entende-se a evolução dos estudos sistemáticos de administração e o desenho do processo histórico de gestão de pessoas.

A evolução histórica do processo de gestão de pessoas, inicia-se com o modelo diretivo, com a Administração Científica, proposta por Taylor, que tinha como objetivo

proporcionar fundamentação científica às atividades administrativas, substituindo a improvisação e o empirismo. Nesse sentido, fundamentava-se na racionalização do trabalho, mais especificamente na simplificação dos movimentos requeridos para a realização de uma tarefa, objetivando a redução do tempo desta. Outro estudioso que contribuiu para a Administração científica foi Henry Ford afirmando que o trabalho deveria ser altamente especializado, no qual cada operário deveria realizar apenas uma tarefa, reduzindo dessa forma o tempo de dedicação (GIL, 2001).

O movimento da Administração científica difundiu-se rapidamente e tornou-se uma das principais bases da organização industrial nas primeiras décadas do século, ao mesmo tempo Fayol, com a abordagem administrativa, buscava focar no gerente da empresa, estudando os melhores comportamentos que esses deveriam desempenhar com seus funcionários, para que a produtividade crescesse. As funções do gerente seriam então: planejar, organizar, liderar e controlar.

Nesse período, conforme críticas de Souza e Ferreira (2004), as abordagens administrativas ainda focavam muito no poder produtivo das máquinas e, com base nesse pensamento, procurava fazer com que toda a organização, incluindo os seus trabalhadores 
fossem gerenciados com a lógica mecânica. Ainda se possuía uma visão muito limitada do ser humano, no qual ele era orientado apenas por interesse financeiro e um era considerado um bom empregado aquele passivo e totalmente submisso às ordens do superior. Além disso, não viam o contexto em que a organização estava inserida, dando pouca ênfase na influência dos aspectos sociais, políticos e ambientais envolvidos na gestão.

A partir desse momento, nota-se que fatores psicológicos e sociais deveriam ser considerados na produtividade e deixa-se de lado o modelo diretivo e inicia-se o modelo participativo, com um novo movimento chamado de Escola das Relações Humanas.

Esse movimento buscou estudar o ambiente adequado para se trabalhar, para isso Mayo, propôs estudar a influência da iluminação na produtividade. Obteve como resultado que o grau de luminosidade não interferia, e sim, o que interferia era o sentimento de valorização dos funcionários pela participação na pesquisa. Dessa forma, percebeu-se que fatores psicológicos e sociais tinham influência no produto final do trabalho, como conseqüência passou-se a valorizar as relações humanas no trabalho. As relações humanas constituem um processo de integração de indivíduos numa situação de trabalho, de modo que os trabalhadores colaborem com a empresa e até encontrem satisfação de suas necessidades sociais e psicológicas (GIL, 2001).

Nesse mesmo momento, Hezberg estudava a motivação dos funcionários, e trouxe como contribuição, na busca da produtividade, a teoria de motivação. Esta qual diz que existem dois pólos diferenciados de satisfação e insatisfação. Sendo a satisfação algo intrínseco à atividade desempenhada e a insatisfação aos fatores relacionados ao contexto de trabalho.

Nesse sentido, a insatisfação estaria relacionada aos fatores higiênicos, ou seja, fatores mínimos de sobrevivência no ambiente de trabalho, que evitam a insatisfação mas não geram satisfação. Já a satisfação estaria relacionada com os fatores motivacionais, fatores esses que deveriam está relacionados com a atividade desempenhada, enriquecimento do cargo, tornando assim a atividade mais interessante e prazerosa, com conseqüente satisfação no trabalho.

Na década de 60, começa-se a falar em Administração de Recursos Humanos devido à introdução de conceitos originários da Teoria Geral dos Sistemas à gestão de pessoal. Definindo sistema como um conjunto de partes unidas entre si que mantenham uma relação e que o comportamento do todo seja o foco, uma organização estaria encaixada no sentido de ser um sistema, constituído de elementos que de alguma forma interagem entre si e funcionam 
como uma estrutura organizada (GIL, 2001). Dessa forma, os funcionários seriam vistos como partes de um todo que visam um objetivo comum.

Esse movimento vem introduzir um novo caráter à área de gestão de pessoas: o caráter estratégico. O motivo seria que essa deveria buscar o melhor encaixe possível com as políticas empresariais e os fatores ambientais. Para isso, os planos estratégicos dos vários processos de gestão de pessoas seriam derivados das estratégias corporativas da empresa (FISHER, 2002).

Assim, a área de gestão de pessoas passaria a ocupar um espaço de diferenciação dentro da empresa, já que as metas e estratégias da empresa somente seriam alcançadas se o desempenho humano estivesse em sintonia e totalmente vinculado com essa, pois as pessoas conseguem transformar tais estratégias em ações práticas. Para isso, devem ser priorizadas o desenvolvimento de competências e de características culturais necessárias para adequar as práticas de Gestão de Pessoas às necessidades da empresa

Segundo Silva (2002), o papel da área de Gestão de Pessoas para se tornar um setor estratégico de uma organização e adicionar valor à esta, é desenvolver ações estratégicas que busquem a construção de competências que possam suportar, otimizar e canalizar esforços para a superação de novos desafios organizacionais. Nesse sentido o objetivo da área seria desenvolver e estimular as competências humanas necessárias para que as competências organizacionais da empresa se viabilizem

Nesse contexto, nasce um novo conceito para denominar os diversos comportamentos de um funcionário dentro da empresa: conceito de competência. O desempenho do trabalhador passa a ser medido pelos diversos conhecimentos, habilidades e atitudes exigidas para o desempenho de suas atividades.

No entanto, são muitas as definições para a expressão “competência individual”, além de divergências de caráter filosófico e ideológico, também são tratadas por diferentes enfoques e em áreas distintas do conhecimento. Dessa forma, segundo Kilimnik e Sant’Anna (2006), prevalecem duas correntes principais: a inglesa e a francesa.

Segundo esses autores, representantes americanos, como McClelland e Dailey (1972) e Spencer e Spencer (1993), definem competência como um conjunto de características individuais observáveis (características subjacentes ao indivíduo) que se relacionam a um critério de eficácia e/ou desempenho superior na execução de um trabalho ou vivência de uma situação.

A corrente francesa, com representantes como Dubar (1998), tem a concepção de competência como um conjunto de saberes mobilizados em situação de trabalho, obtidos de várias formas como transferência de aprendizagem e adaptação, os quais dá a capacidade ao 
sujeito de criar uma base de conhecimentos e habilidades capazes de resolução de problemas em situações concretas. Segundo Le Boterf (1994), a competência não é um estado, nem um conhecimento que se possui, pois nem sempre pessoas que dispõem dela são capazes de mobilizá-las em situações de trabalho; são contingenciais por serem exercidas num contexto particular, guiado por um sistema de valores, de significações e por modelos que são socialmente compartilhados. Assim, traz à tona o fato de a competência não está dissociada das políticas e práticas organizacionais, devendo ser estudada e desenvolvida de acordo com o ambiente organizacional.

Apesar das diversas concepções, a competência é definida como um conjunto de capacidades pessoais, sejam elas de saber, no nível cognitivo, ou fazer, no nível motor, que são necessárias para o desempenho em situações de trabalho.

Atualmente as competências são divididas em duas: competências organizacionais e as individuais. As competências organizacionais são, a missão, a visão e a estratégia de atuação de uma empresa e as competências individuais ou profissionais, os conhecimentos, habilidades e atitudes necessárias para que o funcionário possa apresentar um desempenho adequado para o seu cargo. As competências representam combinações sinérgicas de conhecimentos, habilidades e atitudes, expressas pelo desempenho profissional, dentro de determinado contexto de trabalho (DURAND, 2000; NISEMBAUM, 2000; SANTOS, 2001, apud FREITAS; BRANDÃO, 2006).

Nesse sentido surge a gestão baseada em competência ou gestão de competências, que se propõe a integrar e orientar esforços, sobretudo os relacionados à gestão de pessoas ou seus setores, para desenvolver e sustentar as competências consideradas fundamentais à consecução dos objetivos organizacionais (FREITAS; BRANDÃO, 2006).

A gestão de competências é um processo contínuo cuja etapa inicial é a formulação ou reformulação da estratégia da organização, momento em que seriam definidos a missão, as metas e os seus objetivos. Depois disso, seria realizado um diagnóstico das competências organizacionais necessárias para concretizar tais estratégias e em seguida identificar as lacunas existentes entre as competências necessárias para alcançar tal objetivo e as competências profissionais existentes (competência individual).

Esse diagnóstico é que subsidia as novas ações da área de gestão de pessoas, que seriam desenvolver as competências necessárias ou insuficientes e/ou captá-las no ambiente externo. Essa captação refere-se às ações de recrutamento e seleção de pessoas e o desenvolvimento refere-se ao aprimoramento das competências já existentes. 
O desenvolvimento de competências, parte fundamental desse estudo, se dá por meio de processos de aprendizagem e envolve aquisição de conhecimentos, habilidades e atitudes relevantes a determinado propósito (DURAND, 2000 apud FREITAS; BRANDÃO, 2006). Por ser a ação fundamental desse trabalho, o segundo capítulo apresentará as diversas definições da área de Treinamento, Desenvolvimento e Educação - TD\&E e de seus componentes.

\subsection{Sistema de TD\&E}

Treinamento de pessoal é definido por Goldstein (1991, apud VARGAS; ABBAD, 2006) como aquisição sistemática de atitudes, conceitos, conhecimento, regras e habilidade que resultam em melhoria do desempenho do trabalho.

Para Rosenberg (2001, apud VARGAS; ABBAD, 2006), o treinamento é usado quando é necessário formatar a aprendizagem numa direção específica, ou seja, quando há um estudo sobre a necessidade de treinar tais competências, sobre as características da clientela para adequar a estratégia instrucional e sobre a preparação para avaliar a eficácia do processo.

Definições atuais traduzem a ação de treinamento como uma ação tecnológica controlada pela organização, composta de partes coordenadas, inseridas no sistema organizacional e calcada em conhecimentos advindos de diversas áreas, com o objetivo de promover a melhoria do desempenho, capacitar para o uso de novas tecnologias e preparar para novas funções (PILATI, 2006). Dessa forma, a área de treinamento é uma ação estratégica da organização já que sua finalidade é capacitar os indivíduos focando nas competências específicas da empresa.

Segundo Borges-Andrade (1986 apud PANTOJA; PORTO; MOURÃO; BORGESANDRADE, 2005), treinamento pode ser definido como o modo como os profissionais de educação e treinamento conhecem, compreendem e predizem os aspectos referentes ao ensino e à aprendizagem, e às mudanças de desempenho que se deseja de um determinado indivíduo e o que se faz com o propósito de obter mudanças. O modo como esse enfoque é usado para resolver problemas de treinamento é denominado de Tecnologia Instrucional. Essa tecnologia prevê que o processo de treinamento é composto por elementos que mantêm entre si e com o ambiente externo um relacionamento de interdependência.

São eles: a avaliação de necessidades, planejamento e execução e avaliação de treinamento. Esses componentes mantêm entre si um constante fluxo e informações e produtos, sendo que o subsistema avaliação de treinamento é o principal responsável pelo 
fornecimento de informações para aperfeiçoamento constante do sistema de treinamento (BORGES-ANDRADE, 2006a).

O primeiro componente é a avaliação de necessidades de capacitação, que é definida como o levantamento sistemático de competências nos níveis organizacional, das tarefas e individual. Tem como objetivo identificar e prescrever o alinhamento entre as ações de TD\&E e objetivos organizacionais, que competências devem ser treinadas e quais são as pessoas que devem ser capacitadas (PILATI, 2006). É a partir desse componente que as outras ações são executadas.

O segundo componente é o planejamento e execução que dizem respeito aos métodos e estratégias de treinamento. Segundo Pilati (2006, p.167) “métodos e estratégias proporcionam a criação das condições de aprendizagem, e seu desenvolvimento tecnológico está diretamente ligado ao desenvolvimento de competências em populações específicas, bem como o uso de tecnologias, mudanças de estados afetivos nos treinandos e produção de habilidades complexas”, ou seja, é um componente essencial para que a aprendizagem seja efetiva já que deve está diretamente ligado ás características da clientela e da competência a ser desenvolvida.

O terceiro componente é a avaliação de treinamento que é uma ação sistemática de coleta de informações para viabilizar a emissão de julgamento sobre a efetividade de TD\&E nas organizações (PILATI, 2006). Por ser o componente de estudo da presente pesquisa, a seguir serão apresentados os diversos tipos de avaliação e seus componentes.

\subsection{Avaliação de Treinamento}

Segundo Borges-Andrade (2006b), o sistema instrucional pode ser definido como o conjunto de materiais instrucionais, instrumentos de mensuração e estratégias de ensino que foram sistematicamente planejados e desenvolvidos, baseados em princípios de aprendizagem, objetivando alcançar metas e objetivos. Esses podem ser alcançados imediatamente ou podem ocorrer a longo prazo, e é a avaliação que irá analisar essas informações visando fornecer subsídios úteis para decidir se o programa de capacitação será adotado ou rejeitado. Dessa forma, o sistema de avaliação é o responsável pelo feedback de todo o sistema de avaliação, é ele que irá sustentar o programa de capacitação.

Os resultados imediatos de um programa de capacitação podem ser avaliados por dois tipos de avaliação, propostos por Kirkpatrick (1976) e Hamblin (1978): avaliação de reação e avaliação de aprendizagem. 
Na avaliação de reação é medido o nível de satisfação dos participantes sobre os diversos aspectos do evento de TD\&E, como: utilidade do curso, aplicabilidade, programação e instrutores (ABBAD et al., 2000 apud LACERDA, 2002). São avaliados fatores ambientais e estruturais do curso, que são observados durante o mesmo e que podem acarretar na dificuldade de absorção do conteúdo.

Na avaliação de aprendizagem é medido o nível de assimilação e retenção dos conteúdos e/ou competências indicadas pelo objetivo do curso. Normalmente, são aplicadas provas e testes de conhecimentos medindo o nível de aquisição.

Os resultados a longo prazo podem ser avaliados em três níveis, segundo Hamblin (1978): comportamento no cargo, na qual se verifica se o participante utiliza as competências aprendidas no trabalho; mudança organizacional, que verifica as mudanças que podem ter ocorrido no funcionamento da organização após a aprendizagem e; valor final, que tem o objetivo de avaliar o nível de alteração na produção ou nos serviços prestados pela organização.

A efetividade de um programa de TD\&E pode ser avaliada por esses níveis propostos, entretanto Borges-Andrade (2006a) argumenta que outras características ou variáveis também devem ser levadas em conta, pois podem tornar mais precisa a definição das situações em que o sistema instrucional ocorre e como ele funciona, além de indicar associações entre elas e as características dos participantes e das condições presentes no programa ou no ambiente organizacional.

Dessa forma, para testar as relações entre um conjunto de variáveis específicas e determinados resultados de TD\&E, no nível organizacional, foram desenvolvidos o Modelo de Avaliação Integrado e Somativo de Sistemas Instrucionais (Mais) proposto por BorgesAndrade, em 1982, e o de Abbad (1999), intitulado como Modelo Integrado de Avaliação de Impacto do Treinamento (Impact).

Segundo Borges-Andrade (2006a), o Mais possui cinco componentes que avaliam todo o processo de treinamento de uma organização. São eles: insumos, procedimento, processos, resultados e ambiente. 


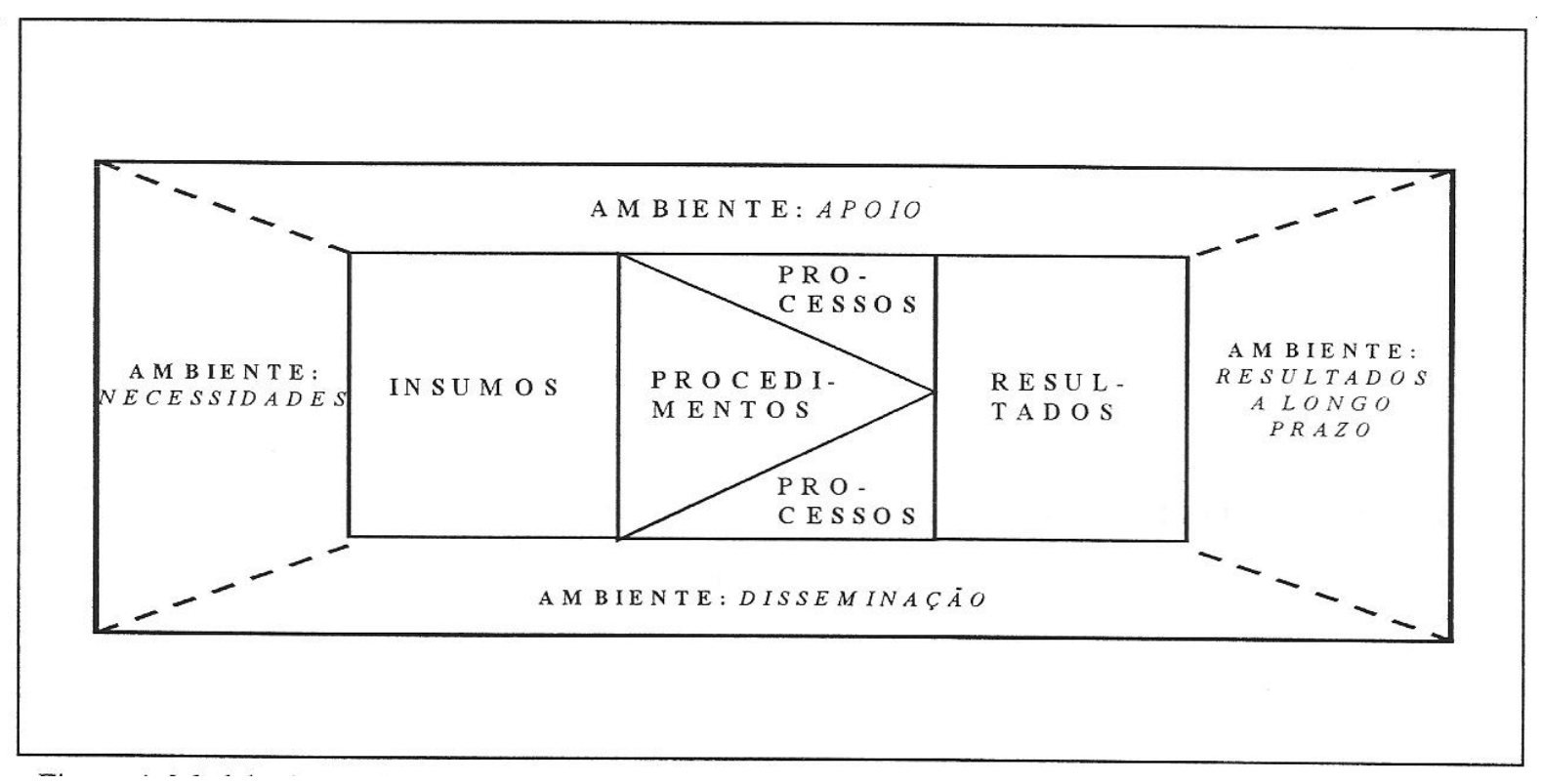

Figura 1 - Modelo de Avaliação Integrado e Somativo - MAIS.

Fonte: Borges-Andrade (2006a, p. 344)

Os insumos referem-se a todos os dados relacionados aos fatores físicos e sociais anteriores à instrução que podem interferir no resultado desta. Os dados demográficos e ocupacionais dos participantes são exemplos de insumos. Sabendo desses dados, o profissional de TD\&E tem a possibilidade de selecionar os eventos mais adequados para essa população, aumentando a probabilidade de que o treinamento seja eficaz.

Os procedimentos são as estratégias instrucionais utilizadas no treinamento, ou seja, as operações necessárias para facilitar ou produzir os resultados esperados. Utilização de aulas expositivas ou de exercícios práticos são exemplos desse componente, já que são variáveis pertencentes ao planejamento instrucional.

Variáveis pertencentes ao comportamento do treinando e que aparecem no decorrer da instrução referem-se ao terceiro componente, o processos. As relações entre os aprendizes, dos aprendizes com o instrutor e o resultado dos exercícios práticos são exemplos desse componente.

O quarto componente é o resultado que se refere ao desempenho dos indivíduos, ou seja, ao desempenho final pretendido ou às conseqüências inesperadas do programa.

O último componente é o ambiente, que são todas as condições, atividades e eventos que fazem parte do programa de TD\&E, ou seja, é o contexto do treinamento. Esse componente pode ser dividido em quatro subcomponentes: avaliação de necessidades, apoio, disseminação e resultados a longo prazo.

O modelo Impact proposto por Abbad (1999), avalia o impacto e investiga diversas variáveis preditivas de eficiência e eficácia do treinamento, que são as seguintes: percepção 
de suporte organizacional, características do treinamento, características da clientela, reação, aprendizagem, suporte à transferência.

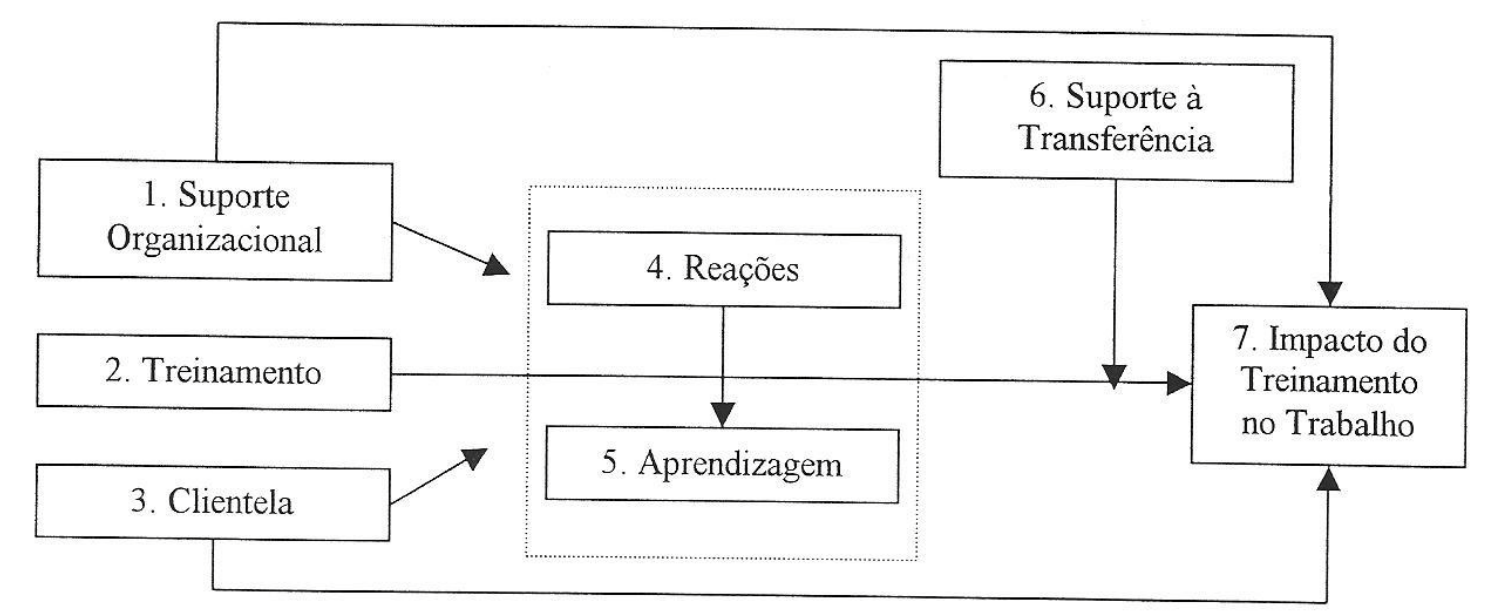

Figura 2 - Modelo Integrado de Avaliação de Impacto do Treinamento no Trabalho - IMPACT. Fonte: Lacerda (2002, p. 12)

A percepção de suporte organizacional representa a opinião dos participantes quanto às práticas organizacionais de gestão do desempenho, valorização do servidor e apoio gerencial ao treinamento. A gestão do desempenho seria a opinião dos participantes acerca das práticas de estabelecimento de metas de trabalho, disponibilização de informações, sistemas de recompensas de desempenho, orientação técnica, profissional e pessoal. A valorização do servidor refere-se à percepção do funcionário sobre as práticas que dão valor e respeito às idéias e sugestões individuais. A variável, apoio gerencial ao treinamento representa a percepção do participante acerca do empenho demonstrado pela chefia para viabilizar a participação dos funcionários em treinamento.

As características do treinamento representam tudo que está relacionado com o treinamento em si, o planejamento instrucional, no qual abarca os objetivos do curso, duração, características da instrutoria, conteúdo programático, material didático, material para apresentação e atividades à serem realizadas. No modelo MAIS, essa variável representa a variável de procedimento, que é definida como as operações e meios utilizados para facilitar ou produzir os resultados esperados do evento.

As características da clientela são os conjuntos de informações demográficas, funcionais, motivacionais e atitudinais referentes aos participantes do evento. As informações motivacionais e atitudinais representam as próprias opiniões acerca do interesse no treinamento, motivação para aprendizagem e intenção de aplicar. Essa variável corresponde 
ao insumo do modelo Mais, que se refere aos dados relacionados aos fatores físicos e sociais anteriores à instrução.

O componente reação refere-se à opinião imediata do participante acerca da programação, apoio ao desenvolvimento do módulo, aplicabilidade e utilidade do treinamento, resultados e desempenho do instrutor. Esse componente refere-se ao componente resultado do modelo Mais, que corresponde ao desempenho final pretendido pelo evento e as conseqüências inesperadas do programa.

O quinto componente é a aprendizagem, que representa o grau de assimilação e retenção dos conteúdos ensinados por ocasião de um evento, medido em termos de escores e obtidos pelo participante em provas ou teste, aplicados ao seu final. Esse componente também é relativo ao componente resultado do modelo Mais.

O sexto componente é o suporte à transferência que avalia o apoio ambiental, do trabalho, ao uso dos novos conhecimentos adquiridos no evento instrucional. Esse componente é classificado em três níveis de análise: fatores situacionais de apoio, suporte material e conseqüências associadas ao uso das novas habilidades. Os fatores situacionais identificam o apoio gerencial, social (dos pares) e organizacional que se recebe para a aplicação do aprendizado no contexto de trabalho. O suporte material refere-se aos recursos materiais e financeiros, que são disponibilizados para que os funcionários consigam aplicar seus novos conhecimentos. E as conseqüências associadas ao uso de novas habilidades se relacionam com as reações dos pares e chefias às tentativas de aplicação das novas competências aprendidas, ou seja, podem ser reações favoráveis ou desfavoráveis, como elogios, indiferença, desconsideração, manifestação de apoio, entre outros.

O impacto do treinamento, variável que depende dessas anteriormente explanadas, é definida, segundo Abbad (1999), como auto-avaliação acerca dos efeitos produzidos pelo evento instrucional nos níveis de desempenho, motivação, autoconfiança e abertura para mudanças no processo de trabalho.

A partir desse modelo, este estudo propõe uma avaliação mais parcimoniosa, que investiga a relação entre as características da clientela, o suporte à transferência e o nível de impacto do treinamento no trabalho. A seguir, serão apresentados os diversos conceitos de impacto do treinamento e seus preditores. 


\subsection{Avaliação de Impacto do Treinamento no Trabalho e seus preditores}

A área de TD\&E não se interessa apenas pelas avaliações feitas imediatamente após o treinamento, mas principalmente pelo efeito do treinamento a longo prazo sobre os níveis de desempenho, pela identificação de fatores redutores e facilitadores do uso das novas competências e das condições necessárias para que esses níveis melhorem (TAMAYO, 2002).

Para isso, foi desenvolvida a avaliação de impacto do treinamento, que possui o objetivo de avaliar se o indivíduo, após a aquisição de certos conhecimentos, habilidades e atitudes necessários para a sua função, apresenta melhorias significativas no seu desempenho.

Essas melhorias se dão através da transferência do aprendizado para o trabalho, sendo transferência de treinamento, a aplicação correta, no ambiente de trabalho, de conhecimentos, habilidades e atitudes adquiridos nesses eventos instrucionais. Aquilo que o participante transfere para o trabalho é uma nova forma de desempenhar antigas atividades e/ou um novo tipo de desempenho (FREITAS et al., 2006).

Pilati e Abbad (2005) propõem uma seqüência de eventos que fariam o programa instrucional surtir efeito no desempenho do funcionário: inicialmente, o participante deveria adquirir as competências propostas, isso permitiria o alcance do segundo evento, a retenção dos conhecimentos e habilidades que está relacionado à generalização dos comportamentos para situações diferentes daquela do evento instrucional, que permitiria, assim, a transferência do aprendizado para o trabalho.

Em síntese, a transferência de aprendizagem significa a mudança na forma de desempenhar as atividades do trabalho, a partir das aprendizagens ocorridas no evento instrucional. Sendo assim, o impacto do treinamento seria a influência ou efeito exercido pelo evento no desempenho subseqüente do participante, ou seja, a produção de mudanças observáveis no desempenho do indivíduo treinado.

Dessa forma, impacto de TD\&E são mudanças significativas no desempenho do indivíduo como resultado da aplicação das competências desenvolvidas pelo treinamento. São dois os tipos de medida que podem ser utilizados para acessar o impacto do treinamento segundo Hamblin (1978, apud TAMAYO, 2002): impacto em amplitude e impacto em profundidade.

A avaliação de profundidade requer o planejamento instrucional, pois necessita de todos os objetivos instrucionais, elaborados em termos de desempenhos mensuráveis, já que precisam ser avaliados posteriormente. A pesquisa em amplitude identifica informações sobre 
a freqüência da utilização do conteúdo ensinado, melhoria da qualidade do desempenho de tarefas gerais e diminuição de erros na execução das tarefas.

Quando o interesse da avaliação reside nos benefícios do treinamento sobre os desempenhos genéricos, muitas vezes não relacionado ao conteúdo aprendido, as medidas utilizadas referem-se ao impacto em amplitude ou largura. Já se o interesse for investigar melhorias em desempenhos subseqüentes, a partir de objetivos instrucionais específicos, as medidas referem-se ao impacto em profundidade (MENESES; ABBAD, 2003). Segundo Freitas et al. (2006, p. 492), “o indicador de profundidade representa o conjunto de melhorias no desempenho em tarefas diretamente relacionadas aos objetivos e conteúdos ensinados no evento de TD\&E.”

Conforme os diversos estudos notam-se que para o desempenho ser eficaz, é necessário um conjunto de condições, na qual Abbad (2004, apud FREITAS et al., 2006) descreve como variáveis individuais, em que as pessoas precisam saber fazer e querer fazer a tarefa e variáveis situacionais, pois as pessoas também necessitam de suporte organizacional para executar o trabalho. Segundo Tannenbaum e Yukl (1992, apud MENESES; ABBAD, 2003), a aprendizagem é necessária, mas não essencial para uma mudança de comportamento no trabalho, pois o ambiente pré e pós-treinamento também desempenha um papel importante nessa mudança.

O conceito de suporte, segundo o senso comum, é usado no sentido de apoio, base, amparo, já na linguagem técnica expressa condições organizacionais necessárias para que se consiga trabalhar e, em alguns casos, o compromisso da organização para com o indivíduo. Percepção dos funcionários quanto à valorização, pela organização, pelo seu superior e pelos seus pares, de suas contribuições; percepção de recursos materiais disponíveis para a transferência de aprendizagem são exemplos de suporte ao treinamento adquirido.

A variável de suporte à transferência vem sendo apontada, tanto em pesquisas nacionais quanto em estrangeiras, como as mais importantes preditoras de impacto do treinamento no trabalho a longo prazo, segundo revisão bibliográfica de Zerbini e Abbad (2005).

Essa variável situacional refere-se ao componente apoio do Modelo de Avaliação Integrado e Somativa - Mais, e ao componente de suporte à transferência do Modelo Impact proposto por Abbad (1999), que é utilizado nesse estudo.

Segundo esses autores, suporte à transferência é a percepção do indivíduo sobre o apoio que recebe de colegas e chefias para aplicar, no trabalho, novas competências adquiridas em treinamento; a cultura de aprendizagem contínua que é o compartilhamento 
funcionários de significados e expectativas acerca de quanto à empresa maximiza os processos de inovação e competitividade, promovendo a aquisição de competências, a fim de modificar o ambiente de trabalho de alguma forma.

Segundo Abbad (1999), outra variável que pode influenciar na eficácia do treinamento são as características da clientela. Conforme Meneses et al. (2006), as características da clientela podem ser classificadas em cinco categorias: repertório de entrada, sociodemográficas, psicossociais, motivacionais e cognitivo-comportamentais.

O repertório de entrada é o conjunto de CHAs, expectativas e experiências adquiridas pelo participante antes do treinamento; sociodemográfica está relacionada ao perfil do treinando (sexo, idade, escolaridade, condição socioeconômica) e perfil profissional e funcional (profissão, tempo de serviço, função, cargo, lotação); psicossociais referem-se as variáveis auto-referentes, lócus de controle, auto-eficácia, comprometimento, e prazer e sofrimento no trabalho; motivacionais referem-se a motivação para aprender e para transferir a aprendizagem, e o valor instrumental da ação educacional e; cognitivo-comportamental que são as estratégias cognitivas e comportamentais e auto-regulatórias utilizadas pelo participante para aprender.

A presente pesquisa irá correlacionar as variáveis Valor Instrumental do Treinamento, Suporte à Transferência e Impacto do Treinamento no Trabalho, com a finalidade de identificar essas possíveis correlações. São poucas as pesquisas que relacionam variáveis motivacionais com os efeitos do treinamento, quando comparada com os estudos acerca da variável de suporte á transferência. A seguir serão apresentados alguns conceitos de motivação e sua influência no impacto do treinamento no trabalho.

\subsection{Características motivacionais da clientela}

Robbins (2005) define motivação “como um processo responsável pela intensidade, direção e persistência dos esforços de uma pessoa para o alcance de uma determinada meta.” Sendo intensidade a quantidade de esforço que a pessoa despende para a realização de uma tarefa, necessitando de um rumo específico e objetivo (direção), para alcançar determinado resultado. A persistência seria o quanto de tempo a pessoa consegue manter seu esforço, ou seja, o comprometimento com a tarefa até que seja alcançado seu objetivo.

Segundo Gondim e Silva (2004), “a motivação pode ser definida como uma ação dirigida a objetivos, sendo auto-regulada, biológica ou cognitivamente, persistente no tempo e ativada por um conjunto de necessidades, emoções, valores, metas e expectativas”. Nesse 
sentido, nota-se uma concordância entre os autores, na qual, a motivação é um fator que impulsiona a pessoa a fazer algo, que o possui um resultado valorativo para ela (recompensa), por isso há a persistência na ação.

Existem diversas teorias, que até corroboram com o crescimento da área de Gestão de Pessoas, que abordam a motivação como processo essencial do ser humano. Embora sejam ainda muito questionáveis sobre sua validade, essas teorias ainda são as explicações mais conhecidas sobra a motivação dos trabalhadores. Neste trabalho, buscou-se apresentar as principais teorias e se focar na teoria de expectativas de Vroom.

A primeira teoria de motivação foi elaborada por Maslow, conhecida como a hierarquia das necessidades. $\mathrm{O}$ autor afirmava que era necessário que o indivíduo percorresse certas necessidades (fisiológica, segurança, social, estima e auto-realização) para que estivesse motivado, sendo que a fisiológica era necessidade mais básica e estaria na base da pirâmide e a auto-realização estaria no topo. Para se motivar um indivíduo seria necessário descobrir em qual dessas etapas ele estava e focar a satisfação naquele nivelou no patamar imediatamente superior.

Outra teoria que trabalhou em cima do modelo da hierarquia de necessidades é a de Aldefer chamada de teoria ERC. Esse autor definiu três grupos de necessidades essências: necessidade de existência (requistos materiais básicos), necessidade de relacionamento (manter relações interpessoais) e necessidade de crescimento (desejo de desenvolvimento pessoal). Diferentemente de Maslow, esta teoria diz que mais de uma necessidade pode estar ativa ao mesmo tempo e se uma necessidade de nível superior for reprimida, o desejo de satisfazer outra de nível inferior aumentará. Assim, a frustração de uma necessidade pode levar à regressão. Essa teoria já traz a importância de verificar outras variáveis ambientais que podem alterar a importância de cada necessidade para uma pessoa.

A teoria de Mc Clelland enfoca três necessidades básicas do indivíduo: necessidade de realização, necessidade de poder e necessidade de associação. Necessidade de realização seria a busca da excelência, de se realizar e obter sucesso; a necessidade de poder seria a de controle sobre os outros e modificação de seus comportamentos e; necessidade de associação que seria o desejo de relacionamentos interpessoais próximos e amigáveis. (ROBBINS, 2005). Para o autor, cada pessoa estaria inclinada para uma dessas necessidades e através de seus comportamentos que isso poderia ser observado.

Atualmente, uma das explicações mais amplamente aceitas sobre motivação é a teoria da expectativa de Vroom. Esta teoria diz que a força da tendência para agir de determinada maneira depende da força da expectativa de esta ação trará certo resultado e da atração que 
este resultado exerce sobre a pessoa, ou seja, sugere-se que o indivíduo vai despender mais energia em uma ação se o resultado desta for altamente valorativo. Conforme Gondim e Silva (2004), a força para ação estaria relacionada com dois fatores: expectativas individuais e avaliação subjetiva das conseqüências esperadas.

As ações seriam escolhidas de forma a maximizar o prazer e o ganho e minimizar as perdas. A escolha, então, seria influenciada por três fatores: valência, instrumentalidade e expectância. A valência é a qualidade positiva ou negativa atribuída aos resultados da ação, ou seja, é o que faz com que a pessoa sinta-se atraída pelo resultado. A instrumentalidade é a percepção clara da relação entre a ação e a obtenção do resultado e a expectância é o grau em que se consegue antecipar os resultados esperados e visualizar sua concretização.

Seguindo esta idéia, considera-se que para que um indivíduo esteja motivado para aplicar o aprendizado é necessário não apenas que ele esteja motivado para aprender ou para transferir, mas que o treinamento possibilite o alcance de outros resultados dentro da organização. Dessa maneira, o indivíduo formula expectativas cognitivas a respeito dos efeitos dos seus comportamentos e do valor relativo que a atribui a cada um destes.

Nesse sentido, observa-se três conceitos essenciais para se entender a motivação de um aprendiz antes, durante e após o treinamento. Seriam eles: motivação para aprender, motivação para transferir e valor instrumental do treinamento.

Segundo Meneses et al. (2006), a motivação para aprender é a direção, a intensidade e a persistência do esforço despendido pelo aprendiz em atividades relacionadas com o treinamento antes, durante e depois o programa de TD\&E. A motivação para transferir é a extensão na qual os indivíduos estão motivados para aplicar o conteúdo aprendido. O valor instrumental seria a percepção do indivíduo de que as novas habilidades adquiridas serão úteis para atingir recompensas de várias naturezas.

A partir disso, observa-se a importância de verificar a motivação dos participantes em programas de TD\&E, já que a transferência do aprendizado depende, possivelmente, do valor que ele trará para o sujeito. Desta maneira, é necessário apresentar aos participantes o valor dos programas instrucionais, que recompensas se podem obter, para que eles se sintam motivados a participar de maneira efetiva e eficaz.

Embora seja clara a influência das características da clientela sobre a efetividade do treinamento no trabalho, são poucas as pesquisas que buscam a relação dessas variáveis (ABBAD, 1999; MENESES, 2004; LACERDA, 2002; MENESES; ABBAD, 2003; TAMAYO; 2002). Além disso, há poucos investimentos da produção de instrumentos para os construtos de Motivação para Aprender, Motivação para Transferir e Valor Instrumental do 
treinamento, entre eles os instrumentos produzidos por Noe Schmitt (1986 apud LACERDA, 2002), Abbad (1999), Lacerda (2002) e Silva (2007). 


\section{MÉTODO}

Nesse capítulo é caracterizada a pesquisa realizada e descritas suas etapas, técnicas e procedimento de coleta e análise dos dados.

\subsection{Tipo de pesquisa}

Segundo o critério de classificação proposto por Vergara (2000), a pesquisa pode ser classificada em relação a dois aspectos: quanto aos fins e quanto aos meios.

Quanto aos fins, a presente pesquisa é descritiva, pois expõe dados representativos de determinado fenômeno. Neste caso, descrevem-se as percepções dos alunos os acerca da aplicabilidade, no contexto de trabalho, dos conhecimentos adquiridos, as percepções sobre o suporte para a transferência do aprendizado e as percepções referentes ao valor instrumental dos cursos. A pesquisa também é aplicada por possuir finalidade prática, já que busca identificar a existência de correlação entre variáveis, o que pode contribuir para a área de gestão corporativa das instituições.

Quanto aos meios, a presente pesquisa é bibliográfica, pois compreende uma revisão de literatura acerca do tema, com base no estudo de informações publicadas em livros, artigos, entre outros e é de campo por procurar realizar-se junto aos alunos das instituições objetos de estudo, já que se pretende analisar a percepção deles acerca da efetividade do curso sobre seu desempenho, o suporte dado para a transferência do aprendizado e o a importância e instrumentalidade dos cursos para alcance de seus objetivos.

\subsection{Participantes da pesquisa}

Os instrumentos foram enviados para 134 alunos do Curso de Especialização em Gestão de Pessoas da Universidade de Brasília e 41 alunos do MBA em Gestão Organizacional, promovido pela Faculdade Estácio de Sá de Juiz de Fora/MG.

A amostra pesquisada é composta por 39 alunos do Curso de Especialização em Gestão de Pessoas e do MBA em Gestão Organizacional, e a seguir serão apresentadas as características demográficas (gênero, idade e nível de escolaridade), as características funcionais (cargo que ocupa) e as características do curso de especialização (Curso de Especialização em Gestão de Pessoas ou MBA em Gestão Organizacional e o ano em que participou do curso). 
Tabela 2 - Resultados descritivos dos dados demográficos, funcionais e do curso.

\begin{tabular}{|c|c|c|c|c|c|}
\hline Variável & $\boldsymbol{F}$ & $\%$ & Variável & $\boldsymbol{F}$ & $\%$ \\
\hline Gênero & \multicolumn{5}{|c|}{ Idade } \\
\hline Masculino & 11 & 28,2 & 20 a 30 anos & 19 & 48,7 \\
\hline Feminino & 28 & 71,8 & 31 a 40 anos & 9 & 23,1 \\
\hline Escolaridade & & & 41 a 50 anos & 9 & 23,1 \\
\hline Especialização & 36 & 92,3 & 51 a 60 anos & 2 & 5,1 \\
\hline Mestrado & 3 & 7,7 & & & \\
\hline Cargo & \multicolumn{5}{|c|}{ Cargo } \\
\hline Recursos Humanos & 13 & 33,3 & Assessor & 1 & 2,6 \\
\hline Psicólogo & 5 & 12,8 & Gerente & 6 & 15,4 \\
\hline Administrador & 7 & 17,9 & Farmacêutico & 1 & 2.6 \\
\hline Estatístico & 1 & 2,6 & Advogado & 1 & 2.6 \\
\hline Editor & 1 & 2,6 & Nutricionista & 1 & 2,6 \\
\hline Supervisor de planejamento & 1 & 2,6 & $\begin{array}{l}\text { Técnico Especialista de } \\
\text { Manutenção }\end{array}$ & 1 & 2,6 \\
\hline Curso & \multicolumn{5}{|c|}{$\begin{array}{c}\text { Ano em que participou } \\
\text { do curso }\end{array}$} \\
\hline Curso de Especialização & 33 & 84,6 & 2008 & 19 & 48,7 \\
\hline em Gestão de Pessoas & & & 2007 & 13 & 33,3 \\
\hline \multirow[t]{3}{*}{ MBA em Gestão Organizacional } & 6 & 15,4 & 2006 & 5 & 12,8 \\
\hline & & & 2005 & 1 & 2,6 \\
\hline & & & Antes de 2004 & 1 & 2,6 \\
\hline
\end{tabular}

Destaca-se que o gênero feminino compõe 71.8\% da amostra. Outro dado importante é que 36 participantes, correspondendo a 92,3\%, possuem especialização. A maioria dos respondentes tem idade entre 20 e 30 anos, isto é 48,7\%. Em seguida estão os 9 participantes (23,1\%) que estão na faixa etária de 31 a 40 anos e de 41 a 50 anos.Quanto às características funcionais, 13 participantes, isto é 33,3\%, são ocupantes do cargos na área de recursos humanos, seguidos de 17,9\% no cargo de administrador e 15,4\% em uma cargo de gerência.

Quanto aos cursos avaliados, destaca-se que os alunos do Cursos de Especialização compõe 84,6\% da amostra e que 48,7\% participaram do curso no ano de 2008.

Nota-se que é uma amostra bem jovem e que é composta por maioria de alunos do Cursos de Especialização em Gestão de Pessoas da Universidade de Brasília.

\subsection{Instrumentos de coleta de dados}

Foram utilizados nesta pesquisa os seguintes instrumentos: Impacto em Amplitude do Curso no Trabalho (que inclui Auto-avaliação de Impacto e Suporte à Transferência) e Valor Instrumental do Curso. Os dados demográficos dos participantes serão coletados no início do 
instrumento de Impacto. A Tabela 2 fornece informações gerais sobre os instrumentos utilizados na coleta de dados e sua respectiva relação com os componentes propostos para essa pesquisa.

Tabela 2. Informações gerais sobre os instrumentos utilizados na pesquisa

\begin{tabular}{|c|c|c|}
\hline \multicolumn{3}{|c|}{ COMPONENTE 1 - IMPACTO DO CURSO NO TRABALHO } \\
\hline QUESTIONÁRIO & ITENS & $\mathrm{N}^{\circ}$ DOS ITENS \\
\hline $\begin{array}{l}\text { Impacto do Curso no Trabalho } \\
\text { (Auto-avaliação) }\end{array}$ & Impacto do Curso no Trabalho & $1-12$ \\
\hline \multicolumn{3}{|c|}{ COMPONENTE 2 - SUPORTE À TRANSFERÊNCIA } \\
\hline QUESTIONARIO & ITENS & $\mathrm{N}^{\circ}$ DOS ITENS \\
\hline Suporte à Transferência percebido pelo & Fatores Situacionais de Apoio & $13-20$ \\
\hline Aluno & Suporte Material & $21-26$ \\
\hline & $\begin{array}{l}\text { Conseqüências Associadas ao Uso de } \\
\text { Novas Habilidades }\end{array}$ & $27-33$ \\
\hline \multicolumn{3}{|c|}{ COMPONENTE 3 - VALOR INSTRUMENTAL DO CURSO } \\
\hline QUESTIONÁRIO & ITENS & $\mathrm{N}^{\circ}$ DOS ITENS \\
\hline Valor Instrumental do Curso & Valor Instrumental do Curso & $1-25$ \\
\hline
\end{tabular}

\subsubsection{Questionário de Impacto do Curso no Trabalho}

O instrumento de Auto-avaliação de Impacto do Curso no trabalho contém as mesmas dimensões, itens e escalas do proposto por Abbad (1999). Tem como objetivo avaliar programas de treinamento já desenvolvidos, em termos da capacidade que possuem de gerar resultados no desempenho do treinando.

O instrumento utilizado refere-se ao Impacto em Amplitude do Curso no Trabalho, isto é, identifica os benefícios do curso sobre os desempenhos genéricos, muitas vezes não relacionado ao conteúdo aprendido.

\subsubsection{Questionário de Suporte à Transferência percebido pelos Alunos}

O instrumento de Suporte à Transferência será utilizado para medir o grau de apoio recebido pelo treinando para o uso eficaz das novas habilidades adquiridas no treinamento. Esse instrumento investiga o quanto estavam presentes, no ambiente de trabalho do treinando, as condições necessárias à transferência de aprendizagem.

Assim como o instrumento de Impacto, o de Suporte à Transferência é idêntico ao proposto por Abbad (1999). Os 22 itens que compõem o instrumento devem ser respondidos de acordo com uma escala de freqüência de 5 pontos do tipo Likert. Os itens apresentam-se divididos em categorias de conteúdo: 1) Fatores situacionais de Apoio - refere-se ao apoio 
gerencial, social ou organizacional à transferência de treinamento; 2) Suporte Material referem-se à qualidade, suficiência e disponibilidade de recursos materiais e financeiros, bem como à adequação do ambiente físico do local de trabalho à transferência de treinamento; e 3) Conseqüências Associadas ao uso das Novas Habilidades - refere-se à percepção do participante acerca da ocorrência de reações dos colegas ou superiores hierárquicos à transferência do treinamento.

\subsubsection{Questionário de Valor Instrumental do Curso}

Para identificar as percepções sobre o Valor Instrumental do Curso será utilizado o instrumento de pesquisa de Silva (2007), construído a partir da Escala de Valor Instrumental do Treinamento de Lacerda (2002). Segunda essa autora, o Valor Instrumental é definido como a importância que o treinando atribui a determinadas recompensas e aos benefícios para o treinando, oriundos da participação no treinamento, relacionados a resultados futuros.

O instrumento de Valor Instrumental do Curso está dividido em duas das dimensões da teoria da expectância proposta por Vroom. A primeira, na investigação da variável valência, na qual corresponde a Importância (valor) atribuída pelo participante aos objetivos profissionais e pessoais por ele almejados e a segunda, na investigação da variável Utilidade (instrumentalidade), que refere-se à avaliação que o participante faz de que o curso foi um meio eficaz para alcançar esses objetivos.

\subsection{Procedimento de coleta e análise dos dados}

A realização da pesquisa com os alunos das instituições de ensino foi precedida de prévia e expressa autorização dos coordenadores dos cursos.

Os instrumentos de avaliação foram digitalizados e disponíveis no site da pesquisa. O link do site foi enviado para o endereço eletrônico dos alunos, com a devida identificação e explicação do objetivo da pesquisa.

Os participantes ao enviarem o questionário respondido, tiveram suas respostas ao instrumento automaticamente transpostas para um banco de dados e em seguida o pesquisador as registrou em um arquivo de dados eletrônico no programa SPSS (Statistical Package for the Social Science), versão 15.0. 
Em um primeiro momento, foram realizadas análises descritivas e exploratórias para investigar a exatidão da entrada dos dados, a distribuição dos casos omissos, o tamanho da amostra, os casos extremos e a distribuição das variáveis.

Em seguida, foram realizadas análises descritivas de cada variável do instrumento de medida utilizado e a correlação, que é definida pelo grau de associação entre variáveis. A correlação indica apenas que as variáveis crescem no mesmo sentido, não indica que uma variável influencia a outra.

Este estudo buscou verificar o grau de relacionamento entre as variáveis Impacto do Curso no Trabalho, Suporte à Transferência e o Valor Instrumental do Curso. Os resultados das análises descritivas e a correlação serão apresentados no capítulo seguinte. 


\section{RESULTADOS}

Nesse capítulo, inicialmente serão discutidos os resultados descritivos de cada variável do presente estudo e em seguida, as análises de correlação entre essas variáveis.

\subsection{Resultados descritivos da variável Impacto em Amplitude}

Na Tabela 3 observa-se os resultados descritivos quanto ao Impacto em Amplitude, que objetivou medir a percepção dos participantes sobre os efeitos gerais do curso no trabalho. A escala de freqüência utilizada apresentava os pontos: 5 - Concordo totalmente com a alternativa; 4 - Concordo com a afirmativa; 3 - Não concordo, nem discordo com a afirmativa; 2 - Discordo um pouco com a afirmativa; 1 - Discordo totalmente com a afirmativa.

Tabela 3 - Resultados descritivos do Impacto em Amplitude

\begin{tabular}{|c|c|c|}
\hline Itens & Média & $\begin{array}{l}\text { Desvio } \\
\text { Padrão }\end{array}$ \\
\hline $\begin{array}{l}\text { 2. Aproveito as oportunidades que tenho para colocar em prática o que me foi ensinado } \\
\text { no curso. }\end{array}$ & 4,36 & 0,54 \\
\hline 8. Minha participação no curso serviu para aumentar minha motivação para o trabalho. & 4,18 & 0,88 \\
\hline $\begin{array}{l}\text { 6. A qualidade do meu trabalho melhorou mesmo naquelas atividades relacionadas ao } \\
\text { conteúdo do curso. }\end{array}$ & 4,05 & 0,79 \\
\hline $\begin{array}{l}\text { 9. Minha participação nesse curso aumentou minha auto-confiança. (Agora tenho mais } \\
\text { confiança na minha capacidade de executar meu trabalho com sucesso). }\end{array}$ & 4,00 & 1,05 \\
\hline $\begin{array}{l}\text { 10. Após minha participação no curso, tenho sugerido, com mais freqüência, mudanças } \\
\text { nas rotinas de trabalho. }\end{array}$ & 3,95 & 1,02 \\
\hline $\begin{array}{l}\text { 3. As habilidades que aprendi no curso fizeram com que eu cometesse menos erros, em } \\
\text { meu trabalho, em atividades relacionadas ao conteúdo do curso. }\end{array}$ & 3,92 & 0,83 \\
\hline 11. Esse curso que fiz tornou-me mais receptivo a mudanças no trabalho. & 3,85 & 0,93 \\
\hline 1. Utilizo, com freqüência, em meu trabalho atual, o que foi ensinado no curso. & 3,74 & 1,07 \\
\hline $\begin{array}{l}\text { 12. O curso que fiz beneficiou meus colegas de trabalho, que aprenderam comigo } \\
\text { algumas novas habilidades. }\end{array}$ & 3,56 & 1,04 \\
\hline $\begin{array}{l}\text { 7. A qualidade do meu trabalho melhorou mesmo naquelas atividades que não pareciam } \\
\text { estar relacionadas ao conteúdo do curso. }\end{array}$ & 3,56 & 0,94 \\
\hline 4. Recordo-me bem dos conteúdos ensinados no curso. & 3,51 & 1,00 \\
\hline 5. Quando aplico o que aprendi no curso, executo meu trabalho com maior rapidez. & 3,38 & 0,96 \\
\hline
\end{tabular}

Nota-se que as médias desse fator estão altas já que ficam entre 3,38 e 4,36, o que significa que os cursos tiveram um bom efeito quanto ao desempenho geral do aluno no seu trabalho. 
Nesta escala de 5 pontos, foram considerados altos os desvios padrão, acima de 0,94. Nesse fator, apenas 4 valores de desvios padrão estão abaixo desse valor, o que representa a percepção diferente e destoante dos alunos quanto ao impacto do curso no desempenho geral de suas atividades. Isso pode ter acontecido devido à diferença de programas instrucionais dos dois cursos de especialização avaliados e às diferentes funções exercidas pelos participantes.

O itens 2 (“Aproveito as oportunidades que tenho para colocar em prática o que me foi ensinado no curso") e 8 ("Minha participação no curso serviu para aumentar minha motivação para o trabalho") obtiverem as maiores médias e desvios padrão mais baixos $(M=4,36$, $\mathrm{DP}=0.54$ e $\mathrm{M}=4,18, \mathrm{DP}=0,88$, respectivamente), ou seja, o curso foi efetivo quanto à esses desempenhos e as opiniões se aproximaram um pouco mais. Além destes, o item 6 "A qualidade do meu trabalho melhorou mesmo naquelas atividades relacionadas ao conteúdo do curso" obteve média alta e desvio padrão $(\mathrm{M}=4,05$ e $\mathrm{DP}=0,79)$ o que demonstra a contribuição do curso na execução das tarefas.

O item 5 ("Quando aplico o que aprendi no curso, executo meu trabalho com maior rapidez”) possuiu a menor média e um desvio padrão moderado ( $\mathrm{M}=3,38$ e $\mathrm{DP}=0,96)$, o que representa que o curso contribuiu pouco para que as tarefas fossem executadas mais rapidamente.

\subsection{Resultados descritivos da variável Suporte à Transferência}

Nas Tabelas 4, 5 e 6 é possível observar os resultados descritivos quanto ao Suporte à transferência do aprendizado. Os alunos avaliaram os itens de acordo com uma escala de freqüência que apresentava os pontos: 5 - Sempre; 4 - Frequentemente; 3 - Algumas vezes; 2 - Raramente; 1 - Nunca.

Essa variável foi subdivida em três fatores, que resultou cada um em uma tabela. São eles: Fatores Situacionais de Apoio (Tabela 4); Suporte Material (Tabela 5) e; Conseqüências Associadas ao Uso de Novas Habilidades (Tabela 6).

Tabela 4 - Resultados descritivos de Fatores Situacionais de Apoio

\begin{tabular}{lcc}
\multicolumn{1}{c}{ Itens } & Média & $\begin{array}{c}\text { Desvio } \\
\text { Padrão }\end{array}$ \\
\hline $\begin{array}{l}\text { 13. Tenho tido oportunidades de usar no meu trabalho as habilidades que aprendi no } \\
\text { curso. }\end{array}$ & 3,51 & 0,79 \\
$\begin{array}{l}\text { 15. O objetivos de trabalho estabelecidos pelo meu chefe encorajam-me a aplicar o que } \\
\text { aprendi no curso. }\end{array}$ & 3,28 & 1,07 \\
\end{tabular}


18. Tenho sido encorajado pela minha chefia imediata a aplicar, no meu trabalho, o que aprendi no curso.

16. Tenho tido oportunidades de praticar habilidades importantes (recém-adquiridas no curso), mas, comumente, pouco usadas no trabalho.

14. Falta-me tempo para aplicar no trabalho o que aprendi no curso.

20. Eu recebo as informações necessárias à correta aplicação das novas habilidades no meu trabalho.

19. Meu chefe imediato tem criado oportunidades para planejar comigo o uso das novas habilidades.

17. Os obstáculos e dificuldades associados à aplicação das novas habilidades que adquiri no curso são identificados e removidos pelo meu chefe.

As médias desse subfator estão entre 2,33 e 3,51, revela-se que os Fatores Situacionais de Apoio dado à transferência do aprendizado é moderado, ou seja, algumas vezes os alunos perceberam o apoio dos seus pares e gerentes. Os desvios padrão foram considerados altos, já que se estabeleceu como alto a partir de 0,94. Como aconteceu com a variável acima, pode ser pelas diferenças entre os cursos e os diferentes cargos ocupados pelos participantes.

A média mais alta foi do item 13 ("Tenho tido oportunidades de usar no meu trabalho as habilidades que aprendi no curso”), com $M=3,51$ e $\mathrm{DP}=0,79$, o que significa que há oportunidades para desempenhar atividades que se referem às habilidades adquiridas no curso.

Por outro lado, a média mais baixa foi do item 18 ("Os obstáculos e dificuldades associados à aplicação das novas habilidades que adquiri no curso são identificados e removidos pelo meu chefe”), com $\mathrm{M}=2,33$ e $\mathrm{DP}=1,00$, representando que no ambiente de trabalho a chefia dificulta a aplicação do aprendizado.

Tabela 5 - Resultados descritivos de Suporte Material

\begin{tabular}{lcc}
\multicolumn{1}{c}{ Itens } & Média & $\begin{array}{c}\text { Desvio } \\
\text { Padrão }\end{array}$ \\
\hline $\begin{array}{l}\text { 23. Os equipamentos, máquinas e materiais por mim utilizados estão em boas condições } \\
\text { de uso. }\end{array}$ & 3,82 & 1,14 \\
$\begin{array}{l}\text { 24. As ferramentas de trabalho (micros, máquinas e similares) são de qualidade } \\
\text { compatível com o uso das novas habilidades. }\end{array}$ & $3,69,98$ \\
$\begin{array}{l}\text { 22. Os móveis, materiais, equipamentos e similares têm estado disponíveis em quantidade } \\
\text { suficiente à aplicação do que aprendi no curso. }\end{array}$ & 3,46 \\
$\begin{array}{l}\text { 21. Minha organização tem fornecido os recursos materiais (equipamentos, materiais, } \\
\text { mobiliário e similares) necessários ao bom uso, no trabalho, das habilidades que aprendi } \\
\text { no curso. }\end{array}$ & 3,38 \\
$\begin{array}{l}\text { 25. O local onde trabalho, no que se refere ao espaço, mobiliário, iluminação, ventilação e } \\
\text { nível de ruído, é adequado à aplicação correta das habilidades que adquiri no curso. }\end{array}$ & 3,36 \\
$\begin{array}{l}\text { 26. Minha organização tem fornecido o suporte financeiro extra (ex.: chamadas } \\
\text { telefônicas de longa distância, viagens ou similares) necessário ao uso das novas } \\
\text { habilidades aprendidas no curso. }\end{array}$ & 2,77 \\
\hline
\end{tabular}


Esse subfator possui médias razoáveis, que indicam que os recursos materiais oferecidos pela organização para aplicação dos conhecimentos adquiridos são razoavelmente adequados. Os desvios padrão desse fator, como os outros fatores avaliados, também são altos, o que demonstra as divergências de opiniões entre os alunos, já que alguns podem trabalhar em locais mais equipados e outros em locais que os materiais são insuficientes. Isso demonstra como as possíveis distinções de funções e local de trabalho podem influenciar no padrão de respostas.

Tabela 6 - Resultados descritivos de Conseqüências Associadas ao Uso de Novas Habilidades

\begin{tabular}{|c|c|c|}
\hline Itens & Média & $\begin{array}{l}\text { Desvio } \\
\text { Padrão }\end{array}$ \\
\hline $\begin{array}{l}\text { 27. Em meu ambiente de trabalho, minhas sugestões, em relação ao que foi ensinado no } \\
\text { curso são levadas em consideração. }\end{array}$ & 3,79 & 0,73 \\
\hline $\begin{array}{l}28 \text { Meus colegas mais experientes apóiam as tentativas que faço de usar no trabalho o } \\
\text { que aprendi no curso. }\end{array}$ & 3,72 & 0,85 \\
\hline $\begin{array}{l}\text { 31. Tenho recebido elogios quando aplico corretamente no trabalho as novas habilidades } \\
\text { que aprendi. }\end{array}$ & 3,44 & 0,88 \\
\hline $\begin{array}{l}\text { 32. Quando tenho dificuldades em aplicar eficazmente as novas habilidades, recebo } \\
\text { orientações sobre como fazê-lo. }\end{array}$ & 2,51 & 1,16 \\
\hline $\begin{array}{l}\text { 30. Minha organização ressalta mais os aspectos negativos (ex.: lentidão, dúvidas) do } \\
\text { que os positivos em relação ao uso das novas habilidades. }\end{array}$ & 2,31 & 1,19 \\
\hline $\begin{array}{l}\text { 29. Aqui, passam despercebidas minhas tentativas que faço de usar no trabalho as novas } \\
\text { habilidades que aprendi no curso. }\end{array}$ & 2,26 & 0,81 \\
\hline $\begin{array}{l}\text { 33. Chamam a minha atenção quando cometo erros ao utilizar as habilidades que adquiri } \\
\text { no curso. }\end{array}$ & 2,13 & 0,87 \\
\hline
\end{tabular}

Esse subfator avalia as conseqüências no trabalho associadas ao aprendizado. As médias indicam que são as conseqüências são moderadas, já que as médias ficaram entre 2,13 e 3,79 .

O item 28 ("Em meu ambiente de trabalho, minhas sugestões, em relação ao que foi ensinado no curso são levadas em consideração”) é que possui média mais alta ( $M=3,79$ e $\mathrm{DP}=0,73$ ). Em contrapartida, o item 34 (“Chamam a minha atenção quando cometo erros ao utilizar as habilidades que adquiri no curso”) é o que possui média mais baixa ( $M=2,13$ e $\mathrm{DP}=0,87)$.

Os desvios padrão desse subfator são os mais baixos do fator suporte à transferência, representando quase uma homogeneidade das respostas dos participantes quanto às conseqüências associadas ao uso das novas habilidades. 


\subsection{Resultados descritivos da variável Valor Instrumental do Curso}

Na Tabelas 7 e 8 notam-se os resultados descritivos quanto ao Valor Instrumental do Curso. A variável foi subdividida em duas dimensões: Valência (Tabela 7) e Instrumentalidade (Tabela 8).

Quanto ao instrumento da variável Valência, os alunos avaliaram os itens conforme uma escala de freqüência que apresentava os pontos: 5 - Totalmente importante; 4 - Muito importante; 3 - Nem muito, nem pouco importante; 2 - Pouco importante; 1 - Nada importante.

Quanto ao instrumento da variável Utilidade, os alunos avaliaram os itens de acordo com uma escala de freqüência com os seguintes pontos: 5 - Completamente útil; 4 - Muito útil; 3 - Nem muito, nem pouco útil; 2 - Pouco útil; 5 - Nada útil.

Tabela 7 - Resultados descritivos da variável Valência

\begin{tabular}{|c|c|c|}
\hline Itens & Média & $\begin{array}{l}\text { Desvio } \\
\text { Padrão }\end{array}$ \\
\hline 3. Melhorar o currículo. & 4,77 & 0,42 \\
\hline 18. Ter uma postura crítica em relação aos processos organizacionais. & 4,62 & 0,63 \\
\hline 1. Resolver problemas de trabalho. & 4,62 & 0,54 \\
\hline 20. Atingir as minhas aspirações pessoais. & 4,59 & 0,75 \\
\hline 19. Atingir as minhas aspirações profissionais. & 4,54 & 0,72 \\
\hline 7. Aumentar as chances de conseguir melhores empregos. & 4,51 & 0,75 \\
\hline 24. Melhorar minha autoconfiança no trabalho. & 4,49 & 0,68 \\
\hline 12. Melhorar o meu desempenho relacionado às tarefas do meu cargo. & 4,49 & 0,68 \\
\hline 4. Aumentar as minhas chances de ascensão na carreira. & 4,44 & 0,75 \\
\hline 25. Melhorar a minha auto-estima. & 4,36 & 0,81 \\
\hline 5. Aumentar o meu salário. & 4,28 & 1,00 \\
\hline 22. Identificar um sentido para a minha vida. & 4,21 & 1,10 \\
\hline 8. Sentir-me mais valorizado pelo meu grupo de trabalho. & 4,18 & 0,85 \\
\hline 21. Identificar um sentido para o meu trabalho. & 4,18 & 0,91 \\
\hline 2. Resolver problemas que não se relacionam diretamente com o trabalho. & 4,03 & 1,06 \\
\hline 15. Aumentar a minha motivação no trabalho. & 4,00 & 0,97 \\
\hline 23. Ampliar a minha participação na sociedade. & 3,97 & 1,15 \\
\hline 17. Assumir mais responsabilidades no trabalho. & 3,97 & 0,98 \\
\hline 14. Melhorar a satisfação com o meu atual trabalho. & 3,90 & 1,09 \\
\hline 11. Melhorar o relacionamento com familiares e amigos. & 3,85 & 1,42 \\
\hline $\begin{array}{l}\text { 13. Melhorar a minha atuação em tarefas não relacionadas diretamente ao meu } \\
\text { cargo. }\end{array}$ & 3,85 & 1,04 \\
\hline 9. Melhorar o relacionamento com meus colegas de trabalho. & 3,77 & 1,24 \\
\hline 16. Aumentar o meu comprometimento com o trabalho. & 3,74 & 1,16 \\
\hline 10. Melhorar o relacionamento com meu chefe. & 3,59 & 1,22 \\
\hline 6. Manter-me em meu emprego atual. & 3,31 & 1,43 \\
\hline
\end{tabular}


Nota-se que a variável Valência obteve médias bem altas, já que ficaram entre 3,31 e 4,77. As médias mais altas e os desvios padrão mais baixos foram do item 3 ("Melhorar meu currículo"), com $\mathrm{M}=4,77$ e $\mathrm{DP}=0,42$, seguidos dos item 18 (“Ter uma postura crítica em relação aos processos organizacionais”) e 1 ("Resolver problemas de trabalho"), que obtiveram a mesma média ( $M=4,62, \mathrm{DP}=0,63$ e $\mathrm{M}=4,62$ e $\mathrm{DP}=0,54$, respectivamente).

A média mais baixa e o desvio padrão mais alto foi do item 6 ("Manter-me em meu emprego atual”), com $\mathrm{M}=3,31$ e $\mathrm{DP}=1,43$. Percebe-se que as respostas a esse instrumento ainda foram divergentes devido ao alto desvio padrão.

Tabela 8 - Resultados descritivos da variável Instrumentalidade

\begin{tabular}{|c|c|c|}
\hline Itens & Média & $\begin{array}{l}\text { Desvio } \\
\text { Padrão }\end{array}$ \\
\hline 3. Melhorar o currículo. & 4,67 & 0,70 \\
\hline 18. Ter uma postura crítica em relação aos processos organizacionais. & 4,44 & 0,71 \\
\hline 4. Aumentar as minhas chances de ascensão na carreira. & 4,28 & 0,97 \\
\hline 7. Aumentar as chances de conseguir melhores empregos. & 4,26 & 0,96 \\
\hline 24. Melhorar minha autoconfiança no trabalho. & 4,13 & 1,00 \\
\hline 19. Atingir as minhas aspirações profissionais. & 4,10 & 0,91 \\
\hline 12. Melhorar o meu desempenho relacionado às tarefas do meu cargo. & 4,10 & 0,91 \\
\hline 8. Sentir-me mais valorizado pelo meu grupo de trabalho. & 4,03 & 0,98 \\
\hline 20. Atingir as minhas aspirações pessoais. & 3,97 & 0,98 \\
\hline 1. Resolver problemas de trabalho. & 3,92 & 0,87 \\
\hline 25. Melhorar a minha auto-estima. & 3,77 & 1,11 \\
\hline 21. Identificar um sentido para o meu trabalho. & 3,77 & 1,08 \\
\hline 17. Assumir mais responsabilidades no trabalho. & 3,72 & 1,14 \\
\hline $\begin{array}{l}\text { 13. Melhorar a minha atuação em tarefas não relacionadas diretamente ao meu } \\
\text { cargo. }\end{array}$ & 3,62 & 1,11 \\
\hline 15. Aumentar a minha motivação no trabalho. & 3,54 & 1,23 \\
\hline 5. Aumentar o meu salário. & 3,51 & 1,55 \\
\hline 16. Aumentar o meu comprometimento com o trabalho. & 3,46 & 1,16 \\
\hline 14. Melhorar a satisfação com o meu atual trabalho. & 3,41 & 1,09 \\
\hline 9. Melhorar o relacionamento com meus colegas de trabalho. & 3,41 & 1,31 \\
\hline 23. Ampliar a minha participação na sociedade. & 3,33 & 1,28 \\
\hline 10. Melhorar o relacionamento com meu chefe. & 3,21 & 1,28 \\
\hline 22. Identificar um sentido para a minha vida. & 3,05 & 1,16 \\
\hline 2. Resolver problemas que não se relacionam diretamente com o trabalho. & 3,03 & 1,13 \\
\hline 6. Manter-me em meu emprego atual. & 2,90 & 1,41 \\
\hline 11. Melhorar o relacionamento com familiares e amigos. & 2,64 & 1,46 \\
\hline
\end{tabular}

As médias desse fator ficaram entre 2,64 e 4,67, o que corresponde a um alto grau de percepção da utilidade do curso para alcançar objetivos pessoais e profissionais.

A média mais alta e o desvio padrão mais baixo foi do item 3 ("Melhorar meu currículo), com M=4,67 e DP=0,70, como no fator Valência e a média mais baixa foi do item 
11 ("Melhorar o relacionamento com familiares e amigos"), com $\mathrm{M}=2,64$ e $\mathrm{DP}=1,46$. Os desvios padrão do fator ficaram altos, o que denota um variedade de percepções.

\subsection{Análise da correlação entre as variáveis}

A Tabela 9 apresenta os resultados das análises da correlação, ou seja, o grau de relacionamento entre as variáveis do estudo (Impacto em Amplitude, Suporte à Transferência - Recursos Materiais, Fatores Situacionais de Apoio, Consequências Associadas ao Uso das Novas Habilidades - Valência e Instrumentalidade).

Tabela 9 - Correlação entre as variáveis

\begin{tabular}{lccccc}
\hline & IA & RM & FA & CA & V \\
\hline Impacto em Amplitude (IA) & 1 & & & & \\
Recursos Materiais (RM) &,- 077 & 1 & & & \\
Fatores Situacionais de Apoio (FA) &, $338^{*}$ &, 315 & 1 & & \\
Consequências Associadas ao Uso das Novas Habilidades &, 315 &, 214 &, $482^{* *}$ & 1 \\
(CA) & & & & & \\
Valência (V) &, 134 &, 307 &, 221 &, 043 & 1 \\
Instrumentalidade (I) & $, 544^{* *}, 141$ &, $395^{*}$ &, 106 &, $426^{* *}$ & 1 \\
\hline
\end{tabular}

${ }^{*} \mathrm{p}<0.05$

$* * \mathrm{p}<0,01$

$\mathrm{N}=39$

Observa-se que a correlação mais forte foi entre Impacto em Amplitude e Instrumentalidade $(\mathrm{r}=0,54)$. A variável Impacto em Amplitude ainda se correlacionou significativamente com Fatores Situacionais de Apoio $(\mathrm{r}=0,33)$. Outras correlações significativas foram entre Fatores Situacionais de Apoio e Consequências Associadas ao Uso das Novas Habilidades $(r=0,48)$ e Valência e Instrumentalidade $(r=0,42)$.

Nota-se que variável Recursos Materiais tem correlações moderadas com Fatores Situacionais de Apoio e Valência ( $r=0,31$ e $r=0,30$, respectivamente).

As correlações mais baixas foram entre Impacto em Amplitude e Recursos Materiais ( $\mathrm{r}$ $=-0,07)$ e Consequências Associadas ao novo Uso das Habilidades e Valência $(r=0,43)$.

Genericamente, foi o Impacto em Amplitude que mais se relacionou com as variáveis do estudo. 


\section{DISCUSSÃO}

Este estudo revela dados concernentes a um tema que ainda é pouco explorado em pesquisas empíricas, mas que demonstra a necessidade de ampliar esse campo exploratório e estabelecer a importância de identificar a relação entre esses aspectos. A partir disso, ressaltase que a presente pesquisa não obteve uma amostra satisfatória, o que impossibilita a generalização dos resultados. Mesmo assim, propõe-se esse estudo como um projeto-piloto que faz ilustrações para pesquisas futuras.

A importância de se mensurar o impacto do treinamento, com o objetivo de avaliar em que medida os esforços despendidos nestas ações efetivamente geram os efeitos desejados, não mais se discute. Mas sabe-se que para que um indivíduo transfira um conhecimento é necessário que esteja empenhado com as atividades do curso (motivação para aprender), motivado para aplicar o conhecimento aprendido (motivação para transferir) e acredite que o curso irá ajudar nas suas tarefas diárias (valor instrumental) (MENESES et al., 2006).

Lacerda (2002), Menezes e Abbad (2003) e Tamayo (2002) investigaram variáveis motivacionais e organizacionais no impacto do treinamento e confirmam o poder preditivo das características individuais sobre o impacto do treinamento no trabalho.

Os resultados e análises descritivas indicaram que as competências ensinadas nos cursos de especialização possuíram um efeito no desempenho do egresso, conforme as médias da variável Impacto em Amplitude que ficaram entre 3,38 e 4,36. O Impacto em Amplitude identifica informações sobre a freqüência da utilização do conteúdo ensinado, melhoria da qualidade do desempenho geral de tarefas e diminuição de erros na execução das tarefas (TAMAYO, 2002). Nesse sentido, os resultados desta pesquisa demonstram que os alunos percebem que o curso trouxe resultados para o desempenho de suas funções.

Apesar da pesquisa não ter como objetivo verificar o Impacto em Profundidade, falase de um resultado em profundidade quando há a utilização das competências aprendidas no contexto de trabalho, mas se a utilização das competências ultrapassar esse efeito e proporcionar mudanças nos processos, no funcionamento das tarefas, ai se fala de Impacto em Amplitude. Não se sabe se o curso analisado proporcionou um efeito em tarefas estritamente relacionadas com as competências ensinadas, mas os resultados denotam que ocorreu um efeito mais geral no desempenho, já que as médias desse fator ficaram entre as escalas de “concordo com a afirmativa” e "não concordo, nem discordo com a afirmativa"

A variável de suporte à transferência vem sendo apontada, tanto em pesquisas nacionais quanto em estrangeiras, como as mais importantes preditoras de impacto do 
treinamento no trabalho a longo prazo, segundo revisão bibliográfica de Zerbini e Abbad (2005). De acordo com Tamayo (2002), alguns pesquisadores têm sugerido que a percepção de obstáculos às tarefas, como equipamentos ou recursos financeiros insuficientes, pode influenciar indiretamente no comportamento do indivíduo, reduzindo sua motivação para aplicação.

A partir da análise de outras pesquisas sobre o assunto, nota-se a importância de tal variável para explicação da efetividade do treinamento, por isso este estudo procurou investigar a percepção dos alunos dos cursos de especialização sobre tais conceitos. Abbad (1999) divide a variável suporte à transferência em três subcomponentes: fatores situacionais de apoio, suporte material e conseqüências associadas ao uso das novas habilidades. Sendo Fatores Situacionais de Apoio, o apoio gerencial, social ou organizacional à transferência de treinamento; Suporte Material, a qualidade, suficiência e disponibilidade de recursos materiais e financeiros, bem como à adequação do ambiente físico do local de trabalho à transferência de treinamento; e Conseqüências Associadas ao uso das Novas Habilidades, refere-se à percepção do participante acerca da ocorrência de reações dos colegas ou superiores hierárquicos à transferência do treinamento.

Conforme médias verificadas nos resultados da pesquisa, os subcomponentes de Suporte à Transferência obtiveram médias moderadas. O subcomponente Fatores Situacionais de Apoio obteve médias que ficaram entre 2,33 e 3,51; o subcomponente Recursos Materiais obteve médias entre 2,77 e 3,82; e o subcomponente Consequências Associadas ao Uso das Novas Habilidades obteve médias entre 2,13 e 3,79.

Em seu estudo, Abbad (1999) identificou que Suporte Organizacional é um importante preditor de Aprendizagem, Impacto e Retenção, e que as principais variáveis preditoras de Impacto do Treinamento no Trabalho pertenciam aos componentes Suporte à Transferência e Reações. Por outro lado, entre as variáveis do componente Características da Clientela, mereceram destaque na pesquisa de Abbad (1999) as variáveis motivacionais, as quais foram preditoras de quase todas as variáveis critério estudadas. Por esse motivo este estudo tem como objetivo investigar o Valor Instrumental dos cursos de especialização e verificar as correlações existentes entre esta variável e o Impacto do Curso no Trabalho e o Suporte à Transferência.

O instrumento de Valor Instrumental do Curso utilizado na pesquisa está dividido em duas das dimensões da teoria da expectância proposta por Vroom. A primeira, na investigação da variável Valência, a qual corresponde a Importância (valor) atribuída pelo participante aos objetivos profissionais e pessoais por ele almejados e a segunda, na investigação da variável 
Utilidade (instrumentalidade), que refere-se à avaliação que o participante faz de que o curso foi um meio eficaz para alcançar esses objetivos.

Conforme resultados da pesquisa, as médias das duas dimensões avaliadas ficaram altas: Valência obteve médias entre 3,31 e 4,77 e Instrumentalidade obteve médias entre 2,64 e 4,67. Nota-se que, apesar dos altos índices de desvios padrão, os participantes percebem que o curso de especialização proporcionou o alcance de alguns objetivos almejados por eles. Ressalta-se que nas duas dimensões do instrumento de Valor Instrumental do Curso, os objetivos de "Melhorar o currículo" e “Ter uma postura crítica em relação aos processos organizacionais” foram os que apresentaram médias mais altas, o que corresponde a uma equivalência entre a importância de tais objetivos e o alcance por meio do curso de especialização.

A partir dos resultados descritivos, que demonstraram as percepções dos alunos sobre o impacto do curso, suporte e valor do curso, seguem-se as correlações entre as variáveis do estudo, ou seja, a identificação do grau de associação entre as variáveis.

As análises das correlações demonstraram uma forte correlação entre Impacto em Amplitude com as variáveis do estudo. Observa-se que a correlação mais significativa foi entre Impacto em Amplitude e Instrumentalidade ( $\mathrm{r}=0,54, \mathrm{p}<0)$, além da correlação com Fatores Situacionais de Apoio $(r=0,33, \mathrm{p}<0)$. Tal correlação com a Instrumentalidade já foi alvo de estudos de outros pesquisadores (ABBAD, 1999; WARR; BRUCE, 1995; COLQUITT; LEPINE; NOE, 2000 apud LACERDA, 2002). Conforme estudo de Lacerda (2002), que objetivou construir e validar uma escala de Valor Instrumental do Treinamento, tal variável apresentou-se como forte preditora do Impacto do Treinamento no Trabalho. Segundo ela, a motivação de um indivíduo para determinado curso e o seu conseqüente impacto no trabalho podem estar vinculados aos ganhos secundários associados ao treinamento, tal como medidos pela escala de Valor Instrumental.

Nesse sentido, é relevante apresentar aos treinandos o valor dos programas instrucionais (que ganhos se pode obter com eles) para que eles se sintam motivados a participar dos programas de treinamento. Programas não relacionados a resultados futuros, desejados pelo indivíduo, poderão não alcançar seus objetivos.

Outras correlações significativas foram entre Fatores Situacionais de Apoio e Consequências Associadas ao Uso das Novas Habilidades ( $r=0,48, p<0)$ e Valência e Instrumentalidade $(\mathrm{r}=0,42, \mathrm{p}<0)$. Possivelmente essas correlações ocorreram devido aos subfatores estarem associados a um fator maior. 
O impacto do TD\&E é a influência ou efeito exercido pelo evento no desempenho subseqüente do participante, ou seja, a produção de mudanças observáveis no desempenho do indivíduo treinado (FREITAS et al., 2006). Os resultados da pesquisa demonstram que os cursos de especialização analisados possuem uma influência sobre os desempenhos mais gerais, a percepção sobre o suporte à transferência do aprendizado foi moderado e o valor instrumental do curso foi considerado muito bom. Além disso, verificou-se que os resultados de predição de pesquisas anteriores se confirmaram com o alto grau de correlação entre o impacto em amplitude e as variáveis de suporte e de valor instrumental. 


\section{CONCLUSÕES E AGENDA DE PESQUISA}

Neste capítulo, serão apresentadas as conclusões relacionadas aos objetivos específicos que serviram de fio condutor para este trabalho e sugerida uma agenda de pesquisa para futuras investigações.

\subsection{Conclusões}

O presente estudo objetivou identificar as percepções dos alunos do Curso de Especialização em Gestão de Pessoas e do MBA em Gestão Organizacional acerca do Impacto do Curso no Trabalho, Suporte à Transferência do aprendizado e Valor Instrumental do Curso e correlacionar tais variáveis.

Conforme foi dito no capítulo anterior, devido ao número insuficiente de respondentes, a proposta dessa pesquisa é iniciar um estudo maior com o objetivo de substanciar tal projeto piloto e realmente inferir dados relevantes.

Desse modo, registra-se a expectativa de que os objetivos específicos que balizaram todo o trabalho não tenham sido alcançados de forma conclusiva, mas pelo menos de forma reflexiva, contribuindo, dentro das limitações teóricas, técnicas e humanas, para o avanço da área em que se insere este estudo.

Os resultados descritivos mostraram que os alunos percebem o efeito do treinamento em desempenhos genéricos. As percepções quanto ao suporte à transferência foram moderadas, indicando que as ações de suporte à transferência podem ser melhoradas. Essas análises também revelaram que os alunos, principalmente quanto aos itens de suporte e impacto em amplitude, respondem com certa heterogeneidade, o que significa que possuem percepções distintas e não concordam entre si. Isso, provavelmente, se deve ao fato dos sujeitos pesquisados possuírem funções e ocuparem cargos diferentes.

Os resultados com base na análise de correlação corroboraram, de forma geral, com a teoria existente sobre o tema. Apresentaram as devidas associações entre o impacto do curso no trabalho, o suporte à transferência e o valor instrumental. Conforme os resultados, para que haja mudanças no desempenho é necessário apoio da organização com relação a um suporte psicossocial, ou seja, apoio dos gerentes e pares na motivação para aplicação e valorização do aprendizado e, oportunidades no contexto de trabalho que exijam a transferência desse conteúdo. 
Conforme Tannenbaum e Yukl (1992 apud MENESES; ABBAD, 2003), a aprendizagem é necessária, mas não essencial para uma mudança de comportamento no trabalho, pois o ambiente pós-treinamento também desempenha um papel importante nessa mudança. Estes resultados evidenciam a relevância do papel que as condições contextuais do trabalho têm de garantir que os treinamentos proporcionados sejam efetivos e eficazes nas mudanças de desempenho.

Além disso, para que o treinamento alcance efetividade, observa-se a importância de verificar a motivação dos participantes em programas de TD\&E, já que a transferência do aprendizado depende, possivelmente, do valor que ele trará para o sujeito. Desta maneira, é necessário apresentar aos participantes o valor dos programas instrucionais, que recompensas se podem obter, para que eles se sintam motivados a participar de maneira efetiva e eficaz.

A pesquisa apresentou limitações quanto à amostra selecionada, já que foi pequena e de áreas de trabalho distintas, o que ocasionou a não identificação de percepções muito homogêneas, que consequentemente, trouxeram diminuições nas médias dos fatores estudados. Seria interessante realizar uma pesquisa com alunos de similares funções e áreas de trabalho, para assim identificar quais os fatores daquele contexto que mais influenciam na efetividade do treinamento.

Genericamente, os cursos de especialização obtiveram o resultado esperado, já que alcançaram muitos dos objetivos pessoais e profissionais dos alunos. O impacto do aprendizado no trabalho se mostrou muito significativo e o suporte á transferência ainda é um pouco deficiente.

\subsection{Agenda de pesquisa}

A partir das colocações das limitações e recomendações do presente estudo, registramse alguns caminhos que poderão ser trilhados por futuros pesquisadores:

a) Continuidade deste estudo, pois, apesar do número de participante ter sido inferior ao desejado, já se observa resultados significativos e válidos. É necessário que se busque outras formas de captação dos resultados já que o envio do instrumento digitalizado não foi eficaz.

b) Realizar heteroavaliações de impacto e de suporte para investigar as percepções dos gestores quanto à efetividade do curso realizado. 


\section{REFERÊNCIAS}

ABBAD, G. Um modelo integrado de avaliação do impacto do treinamento no trabalho IMPACT. Tese (Doutorado) - Universidade de Brasília, Brasília, 1999.

ABBAD, G.; TORRES, C. V. Regressão múltipla stepwise e hierárquica em psicologia organizacional: aplicações, problemas e soluções. Estudos de Psicologia (Natal), v. 7, n. especial, 2002.

ABBAD, G.; MENESES, P.. Lócus de controle: validação de uma escala em situação de treinamento. Estudos de Psicologia, vol. 9, 2004.

BORGES-ANDRADE, J. E. Avaliação integrada e somativa em TD\&E. In: BORGESANDRADE, J. E.; ABBAD, G.; MOURÃO, L.. Treinamento, desenvolvimento e educação em organizações e trabalho: fundamentos para a gestão de pessoas. Porto Alegre: Artmed, 2006a.

BORGES-ANDRADE, J. E. Competência técnica e política do profissional de TD\&E. In: BORGES-ANDRADE, J. E.; ABBAD, G.; MOURÃO, L.. Treinamento, desenvolvimento e educação em organizações e trabalho: fundamentos para a gestão de pessoas. Porto Alegre: Artmed, 2006b.

BRANDÃO, H. P.; GUIMARÃES, T. A. Gestão de competências e gestão de desempenho: tecnologias distintas ou instrumentos de um mesmo construto? Revista de Administração de Empresas (FGV), v. 41, n. 1, 2001.

FISHER, A. L. Um resgate conceitual e histórico dos modelos de gestão de pessoas. In: FLEURY, M. T. L. As pessoas na organização. São Paulo: Editora Gente, 2002.

FRANÇA, A. C. L. Práticas de Recursos Humanos - PRH: conceitos, ferramentas e procedimentos. São Paulo: Atlas, 2008.

FREITAS, I. A. de; BORGES-ANDRADE, J. E.; ABBAD, G.; PILATI, R.. Medidas de impacto de TD\&E no trabalho e nas organizações. In: BORGES-ANDRADE, J. E.; ABBAD, G.; MOURÃO, L.. Treinamento, desenvolvimento e educação em organizações e trabalho: fundamentos para a gestão de pessoas. Porto Alegre: Artmed, 2006.

FREITAS, I. A. de; BRANDÃO, H. P. Trilhas de aprendizagem como estratégia de TD\&E. In: BORGES-ANDRADE, J. E.; ABBAD, G.; MOURÃO, L. Treinamento, desenvolvimento e educação em organizações e trabalho: fundamentos para a gestão de pessoas. Porto Alegre: Artmed, 2006.

GIL, A. C. Gestão de pessoas: enfoque nos papéis ocupacionais. São Paulo: Atlas, 2001.

GONDIM, S. M. G.; SILVA, N.. Motivação no Trabalho. In: ZANELLI, J. C.; BORGESANDRADE, J. E.; BASTOS, A. V. B. Psicologia, organizações e trabalho no Brasil. Porto Alegre: Artmed, 2004.

KILIMNIK, Z. M.; SANT’ANNA, A. de S. Modernidade organizacional, política de gestão de pessoas e competências profissionais. In: BORGES-ANDRADE, J. E.; ABBAD, G.; 
MOURÃO, L. Treinamento, desenvolvimento e educação em organizações e trabalho: fundamentos para a gestão de pessoas. Porto Alegre: Artmed, 2006.

LACERDA, E. R. M. Impacto do treinamento no trabalho: investigando variáveis motivacionais e organizacionais como suas preditoras. Dissertação (Mestrado) Universidade de Brasília, Brasília, 2002.

MENESES, P. P. M.; ABBAD, G. Impacto do Treinamento no Trabalho: Preditores Individuais e Situacionais. Revista de Administração Contemporânea - RAC, v. 7, n. especial, 2003.

MENESES, P. P. M.; ABBAD, G. Preditores individuais e situacionais de auto e heteroavaliação de impacto do treinamento no trabalho. Revista de Administração Contemporânea - RAC, v. 1, n. 1, 2003

MENESES, P. P. M.; ABBAD, G.; ZERBINI, T.; LACERDA, E. R. M.. Medidas de características da clientela em avaliação de TD\&E. In: BORGES-ANDRADE, J. E.; ABBAD, G.; MOURÃO, L. Treinamento, desenvolvimento e educação em organizações e trabalho: fundamentos para a gestão de pessoas. Porto Alegre: Artmed, 2006.

PANTOJA, M. J.; PORTO, J. B.; MOURÃO, L.; BORGES-ANDRADE, J. E.. Valores, suporte psicossocial e impacto do treinamento no trabalho. Estudos de Psicologia (Natal), v. 10, n. 2, mai/ago, 2005.

PILATI, R.. História e importância de TD\&E. In: BORGES-ANDRADE, J. E.; ABBAD, G.; MOURÃO, L. Treinamento, desenvolvimento e educação em organizações e trabalho: fundamentos para a gestão de pessoas. Porto Alegre: Artmed, 2006.

PILATI, R.; ABBAD, G. Análise fatorial confirmatória da escala de impacto do treinamento no trabalho. Psicologia: Teoria e Pesquisa, v. 21, n. 1, jan/abr, 2005.

ROBBINS, S. P., Comportamento Organizacional. Tradução técnica Reynaldo Marcondes. São Paulo: Pearson Prentice Hall, 2005.

SILVA, A. R.; FERREIRA, C. P. Introdução à administração: uma iniciação ao mundo das organizações. Rio de Janeiro: Pontal Ed., 2004.

SILVA, C. R. E. Orientação profissional: utilidade, valor e impacto na gestão da carreira e na vida pessoal. Dissertação (Mestrado) - Universidade de Brasília, Brasília, 2007.

SILVA, M. C. M. Planejamento estratégico de RH e a estratégia. In: BOOG, G.; BOOG, M. Manual de gestão de pessoas e equipes: estratégias e tendências. São Paulo: Editora Gente, 2002.

TAMAYO, N. Autoconceito profissional, suporte à transferência e impacto do treinamento no trabalho. Dissertação (Mestrado) - Universidade de Brasília, Brasília, 2002. 
VARGAS, M. R. M.; ABBAD, G. Bases conceituais em treinamento, desenvolvimento e educação - TD\&E. In: BORGES-ANDRADE, J. E.; ABBAD, G.; MOURÃO, L. Treinamento, desenvolvimento e educação em organizações e trabalho: fundamentos para a gestão de pessoas. Porto Alegre: Artmed, 2006.

VERGARA, S. C. Projetos e relatórios de pesquisa em Administração. São Paulo: Atlas, 2000.

ZERBINI, T.; ABBAD, G. Impacto do treinamento no trabalho via internet. Revista de Administração de Empresas (FGV) - RAE eletrônica. v. 4, n. 2, jul/dez., 2005. 
ANEXO 


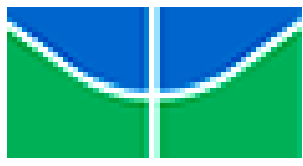

UNIVERSIDADE DE BRASÍLIA - UnB

FACULDADE DE ECONOMIA, ADMINISTRAÇÃO,

CONTABILIDADE E CIÊNCIA DA INFORMAÇÃO E

DOCUMENTAÇÃO - FACE

PROGRAMA DE PÓS-GRADUAÇÃO EM ADMINISTRAÇÃO - PPGA

QUESTIONÁRIO DE AVALIAÇÃO DE IMPACTO DO CURSO NO TRABALHO

\begin{tabular}{|r|r|}
\hline Cargo/Função Atual: & \\
\hline Idade: & \\
\hline Ano em que participou do curso: & \\
\hline Escolaridade: & \\
\hline Sexo: & \\
\hline Curso: & \\
\hline
\end{tabular}

\section{Caro Aluno (a),}

Este questionário é parte da pesquisa de monografia de aluna egressa da V Turma do Curso de Especialização em Gestão de Pessoas da Universidade de Brasília.

As informações prestadas por você serão confidenciais, tratadas de forma agrupada e em conjunto com outros dados obtidos junto aos alunos do curso.

As respostas dadas irão compor um relatório e subsidiar a avaliação e o aprimoramento dos cursos de Especialização.

Leia atentamente o conteúdo dessas afirmativas e avalie o quanto cada uma delas descreve o que você pensa a respeito do impacto exercido pelo curso acima mencionado no trabalho que você realiza, considerando para tal, o período transcorrido desde o término do mesmo até a data de hoje.

Pense também no apoio que vem recebendo para usar no seu trabalho o que aprendeu no curso.

Para responder a cada questão, escolha o ponto da escala que melhor descreve a sua situação e selecione o número correspondente.

\begin{tabular}{|c|c|c|c|c|}
\hline $\mathbf{5}$ & $\mathbf{4}$ & $\mathbf{3}$ & $\mathbf{2}$ & $\mathbf{1}$ \\
\hline $\begin{array}{c}\text { Concordo } \\
\text { totalmente com a } \\
\text { afirmativa }\end{array}$ & $\begin{array}{c}\text { Concordo com a } \\
\text { afirmativa }\end{array}$ & $\begin{array}{c}\text { Não concordo, nem } \\
\text { discordo da afirmativa }\end{array}$ & $\begin{array}{c}\text { Discordo um pouco da } \\
\text { afirmativa }\end{array}$ & $\begin{array}{c}\text { Discordo } \\
\text { totalmente } \\
\text { da } \\
\text { afirmativa }\end{array}$ \\
\hline
\end{tabular}

\section{Impacto do Curso no Trabalho}

( ) 1. Utilizo, com freqüência, em meu trabalho atual, o que foi ensinado no curso.

( ) 2. Aproveito as oportunidades que tenho para colocar em prática o que me foi ensinado no curso.

( ) 3. As habilidades que aprendi no curso fizeram com que eu cometesse menos erros, em meu trabalho, em atividades relacionadas ao conteúdo do curso.

( ) 4. Recordo-me bem dos conteúdos ensinados no curso.

( ) 5. Quando aplico o que aprendi no curso, executo meu trabalho com maior rapidez.

( ) 6. A qualidade do meu trabalho melhorou mesmo naquelas atividades relacionadas ao conteúdo do curso

( ) 7. A qualidade do meu trabalho melhorou mesmo naquelas atividades que não pareciam estar relacionadas ao conteúdo do curso.

( Minha participação no curso serviu para aumentar minha motivação para o trabalho.

( ) 9. Minha participação nesse curso aumentou minha auto-confiança. (Agora tenho mais confiança na minha 
capacidade de executar meu trabalho com sucesso).

( ) 10. Após minha participação no curso, tenho sugerido, com mais freqüência, mudanças nas rotinas de trabalho.

( ) 11. Esse curso que fiz tornou-me mais receptivo a mudanças no trabalho.

( ) 12. O curso que fiz beneficiou meus colegas de trabalho, que aprenderam comigo algumas novas habilidades.

Para responder às próximas questões, utilize a escala abaixo:

\begin{tabular}{|c|c|c|c|c|}
\hline $\mathbf{5}$ & $\mathbf{4}$ & $\mathbf{3}$ & $\mathbf{2}$ & $\mathbf{1}$ \\
\hline Sempre & Freqüentemente & Algumas vezes & Raramente & Nunca \\
\hline
\end{tabular}

\section{Fatores Situacionais de Apoio}

( ) 13. Tenho tido oportunidades de usar no meu trabalho as habilidades que aprendi no curso.

( ) 14. Falta-me tempo para aplicar no trabalho o que aprendi no curso.

( ) 15. Os objetivos de trabalho estabelecidos pelo meu chefe encorajam-me a aplicar o que aprendi no curso.

( ) 16. Tenho tido oportunidades de praticar habilidades importantes (recém-adquiridas no curso), mas, comumente, pouco usadas no trabalho.

( ) 17. Os obstáculos e dificuldades associados à aplicação das novas habilidades que adquiri no curso são identificados e removidos pelo meu chefe.

( ) 18. Tenho sido encorajado pela minha chefia imediata a aplicar, no meu trabalho, o que aprendi no curso.

( ) 19. Meu chefe imediato tem criado oportunidades para planejar comigo o uso das novas habilidades.

( 20. Eu recebo as informações necessárias à correta aplicação das novas habilidades no meu trabalho.

\section{Suporte Material}

( ) 21. Minha organização tem fornecido os recursos materiais (equipamentos, materiais, mobiliário e similares) necessários ao bom uso, no trabalho, das habilidades que aprendi no curso.

( 22. Os móveis, materiais, equipamentos e similares têm estado disponíveis em quantidade suficiente à aplicação do que aprendi no curso.

( 23. Os equipamentos, máquinas e materiais por mim utilizados estão em boas condições de uso.

( ) 24. As ferramentas de trabalho (micros, máquinas e similares) são de qualidade compatível com o uso das novas habilidades.

( 25. O local onde trabalho, no que se refere ao espaço, mobiliário, iluminação, ventilação e nível de ruído, é adequado à aplicação correta das habilidades que adquiri no curso.

( ) 26. Minha organização tem fornecido o suporte financeiro extra (ex.: chamadas telefônicas de longa distância, viagens ou similares) necessário ao uso das novas habilidades aprendidas no curso.

\section{Conseqüências Associadas ao Uso das Novas Habilidades}

( 27. Em meu ambiente de trabalho, minhas sugestões, em relação ao que foi ensinado no treinamento são levadas em consideração.

( ) 28 Meus colegas mais experientes apóiam as tentativas que faço de usar no trabalho o que aprendi no curso.

( ) 29. Aqui, passam despercebidas minhas tentativas que faço de usar no trabalho as novas habilidades que aprendi no curso.

( 30. Minha organização ressalta mais os aspectos negativos (ex.: lentidão, dúvidas) do que os positivos em relação ao uso das novas habilidades.

( ) 31. Tenho recebido elogios quando aplico corretamente no trabalho as novas habilidades que aprendi.

( 32. Quando tenho dificuldades em aplicar eficazmente as novas habilidades, recebo orientações sobre como fazê-lo. 
( ) 33. Chamam a minha atenção quando cometo erros ao utilizar as habilidades que adquiri no curso.

Caso considere necessário tecer algum comentário sobre os itens avaliados, utilize o espaço abaixo.

Obrigado por responder ao questionário! 


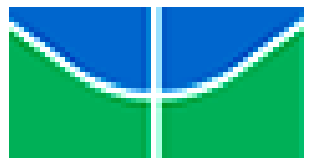

UNIVERSIDADE DE BRASÍLIA - UnB

FACULDADE DE ECONOMIA, ADMINISTRAÇÃO,

CONTABILIDADE E CIÊNCIA DA INFORMAÇÃO E

DOCUMENTAÇÃO - FACE

PROGRAMA DE PÓS-GRADUAÇÃO EM ADMINISTRAÇÃO - PPGA

QUESTIONÁRIO DE AVALIAÇÃO DO VALOR INSTRUMENTAL DO CURSO

\begin{tabular}{|r|r|}
\hline Cargo/Função Atual: & \\
\hline Idade: & \\
\hline Ano em que participou do curso: & \\
\hline Escolaridade: & \\
\hline Sexo: & \\
\hline Curso: & \\
\hline
\end{tabular}

As afirmativas seguintes foram elaboradas para que você indique:

- A IMPORTÂNCIA de cada item para sua vida, independentemente das habilidades que você aprendeu no Curso.

- A UTILIDADE das habilidades aprendidas nesse curso para a consecução de cada item.

Para responder, escolha o número que corresponde à sua opinião para cada item, na coluna de IMPORTÂNCIA e posteriormente na coluna de UTILIDADE, utilizando as escalas abaixo.

Lembre-se de responder todos os itens, preenchendo as duas colunas. Caso contrário sua resposta será inválida.

Embora seja necessária a sua identificação, suas respostas serão tratadas de forma agrupada e em conjunto com outras informações obtidas junto a uma amostra de participantes da oficina o que garante a

confidencialidade de suas respostas individuais.

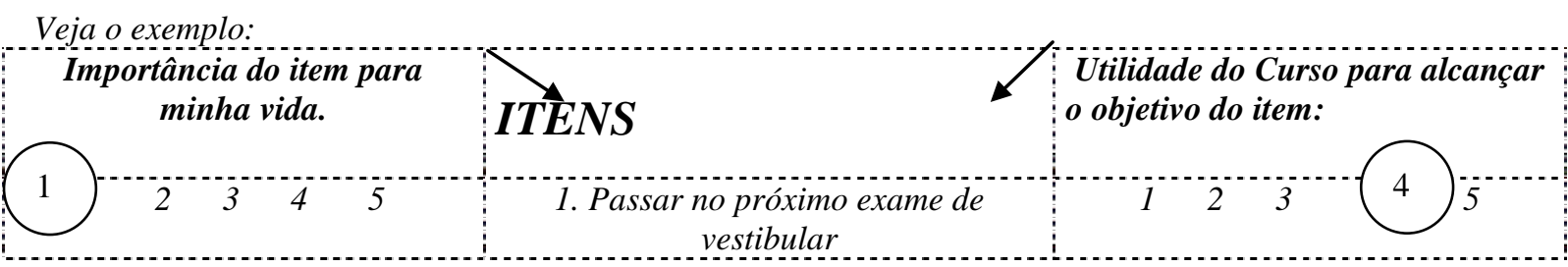

IMPORTÂNCIA

\begin{tabular}{|lcccr|}
\hline 1 & 2 & 3 & 4 & 5 \\
Nada importante & & Totalmente & Importante \\
\hline
\end{tabular}

Quanto mais próximo do 1 você se posicionar, menos importante você considera o item.

Quanto mais próximo do 5 você se posicionar, mais importante você considera o item.

\section{UTILIDADE}

\begin{tabular}{|lrcc|}
\hline 1 & 3 & 4 & 5 \\
Nada Útil & & & Completamente Útil \\
\hline
\end{tabular}

Quanto mais próximo do 1 você se posicionar, menos utilidade você atribui ao item. Quanto mais próximo do 5 você se posicionar, mais utilidade você atribui ao item.

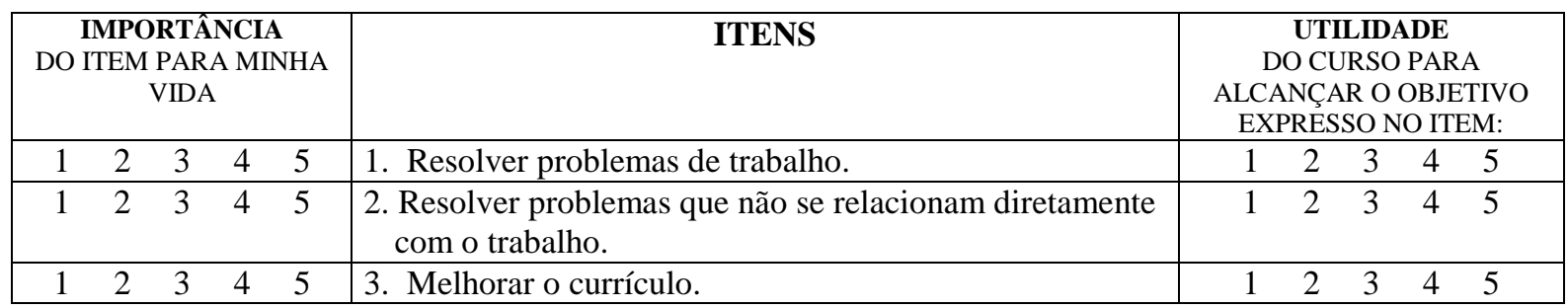




\begin{tabular}{|c|c|c|c|c|c|c|c|c|c|c|}
\hline 1 & 2 & 3 & 4 & 5 & 4. Aumentar as minhas chances de ascensão na carreira. & 1 & 2 & 3 & 4 & 5 \\
\hline 1 & 2 & 3 & 4 & 5 & 5. Aumentar o meu salário. & 1 & 2 & 3 & 4 & 5 \\
\hline 1 & 2 & 3 & 4 & 5 & 6. Manter-me em meu emprego atual. & 1 & 2 & 3 & 4 & 5 \\
\hline 1 & 2 & 3 & 4 & 5 & 7. Aumentar as chances de conseguir melhores empregos. & 1 & 2 & 3 & 4 & 5 \\
\hline 1 & 2 & 3 & 4 & 5 & 8. Sentir-me mais valorizado pelo meu grupo de trabalho. & 1 & 2 & 3 & 4 & 5 \\
\hline 1 & 2 & 3 & 4 & 5 & $\begin{array}{l}\text { 9. Melhorar o relacionamento com meus colegas de } \\
\text { trabalho. }\end{array}$ & 1 & 2 & 3 & 4 & 5 \\
\hline 1 & 2 & 3 & 4 & 5 & 10. Melhorar o relacionamento com meu chefe. & 1 & 2 & 3 & 4 & 5 \\
\hline 1 & 2 & 3 & 4 & 5 & 11. Melhorar o relacionamento com familiares e amigos. & 1 & 2 & 3 & 4 & 5 \\
\hline 1 & 2 & 3 & 4 & 5 & $\begin{array}{l}\text { 12. Melhorar o meu desempenho relacionado às tarefas } \\
\text { do meu cargo. }\end{array}$ & 1 & 2 & 3 & 4 & 5 \\
\hline 1 & 2 & 3 & 4 & 5 & $\begin{array}{l}\text { 13. Melhorar a minha atuação em tarefas não } \\
\text { relacionadas diretamente ao meu cargo. }\end{array}$ & 1 & 2 & 3 & 4 & 5 \\
\hline 1 & 2 & 3 & 4 & 5 & 14. Melhorar a satisfação com o meu atual trabalho. & 1 & 2 & 3 & 4 & 5 \\
\hline 1 & 2 & 3 & 4 & 5 & 15. Aumentar a minha motivação no trabalho. & 1 & 2 & 3 & 4 & 5 \\
\hline 1 & 2 & 3 & 4 & 5 & 16. Aumentar o meu comprometimento com o trabalho. & 1 & 2 & 3 & 4 & 5 \\
\hline 1 & 2 & 3 & 4 & 5 & 17. Assumir mais responsabilidades no trabalho. & 1 & 2 & 3 & 4 & 5 \\
\hline 1 & 2 & 3 & 4 & 5 & $\begin{array}{l}\text { 18. Ter uma postura crítica em relação aos processos } \\
\text { organizacionais. Planejar a minha carreira profissional. }\end{array}$ & 1 & 2 & 3 & 4 & 5 \\
\hline 1 & 2 & 3 & 4 & 5 & 19. Atingir as minhas aspirações profissionais & 1 & 2 & 3 & 4 & 5 \\
\hline 1 & 2 & 3 & 4 & 5 & 20. Atingir as minhas aspirações & 1 & 2 & 3 & 4 & 5 \\
\hline 1 & 2 & 3 & 4 & 5 & 21. Identificar um sentido para o meu trabalho & 1 & 2 & 3 & 4 & 5 \\
\hline 1 & 2 & 3 & 4 & 5 & 22. Identificar um sentido para a minha vida & 1 & 2 & 3 & 4 & 5 \\
\hline 1 & 2 & 3 & 4 & 5 & 23. Ampliar a minha participação na sociedade & 1 & 2 & 3 & 4 & 5 \\
\hline 1 & 2 & 3 & 4 & 5 & 24. . Melhorar minha autoconfiança no trabalho. & 1 & 2 & 3 & 4 & 5 \\
\hline 1 & 2 & 3 & 4 & 5 & 25. Melhorar a minha auto-estima & 1 & 2 & 3 & 4 & 5 \\
\hline
\end{tabular}

Caso considere necessário tecer algum comentário sobre os itens avaliados, utilize o espaço abaixo. 